\title{
Automated terrestrial laser scanning with near-real-time change detection - monitoring of the Séchilienne landslide
}

\author{
Ryan A. Kromer ${ }^{1,2}$, Antonio Abellán ${ }^{1,2,3}$, D. Jean Hutchinson ${ }^{2}$, Matt Lato ${ }^{2,5}$, Marie-Aurelie Chanut ${ }^{4}$, \\ Laurent Dubois ${ }^{4}$, and Michel Jaboyedoff ${ }^{1}$ \\ ${ }^{1}$ Risk Analysis Group, University of Lausanne, Lausanne, Switzerland \\ ${ }^{2}$ Geomechanics Group, Geological Sciences and Geological Engineering, Queen's University, \\ Kingston, Ontario, Canada \\ ${ }^{3}$ Scott Polar Research Institute, University of Cambridge, Cambridge, UK \\ ${ }^{4}$ Groupe Risque Rocheux et Mouvements de Sols (RRMS), Cerema Centre-Est, France \\ ${ }^{5}$ BGC Engineering, Ottawa, Canada \\ Correspondence to: Ryan A. Kromer (ryan.kromer@queensu.ca)
}

Received: 23 January 2017 - Discussion started: 30 January 2017

Revised: 11 April 2017 - Accepted: 20 April 2017 - Published: 24 May 2017

\begin{abstract}
We present an automated terrestrial laser scanning (ATLS) system with automatic near-real-time change detection processing. The ATLS system was tested on the Séchilienne landslide in France for a 6-week period with data collected at $30 \mathrm{~min}$ intervals. The purpose of developing the system was to fill the gap of high-temporal-resolution TLS monitoring studies of earth surface processes and to offer a cost-effective, light, portable alternative to ground-based interferometric synthetic aperture radar (GB-InSAR) deformation monitoring. During the study, we detected the flux of talus, displacement of the landslide and pre-failure deformation of discrete rockfall events. Additionally, we found the ATLS system to be an effective tool in monitoring landslide and rockfall processes despite missing points due to poor atmospheric conditions or rainfall. Furthermore, such a system has the potential to help us better understand a wide variety of slope processes at high levels of temporal detail.
\end{abstract}

\section{Introduction}

terrestrial laser scanning (TLS) is extensively used in the earth sciences to understand and monitor earth surface properties and processes (Eitel et al., 2016). It is commonly used to create dense three-dimensional (3-D) point clouds or digital elevation models to map and characterize the earth surface, and to better understand surface processes by comparing multiple acquisitions over time. Dense 3-D data are also used to quantify and characterize natural hazards (Jaboyedoff et al., 2012) and to monitor hazard processes (Barbarella, 2013; Rosser et al., 2005; Royán et al., 2013; Travelletti et al., 2008). The use of TLS and other remote sensing technologies now forms an important part of natural hazard risk management approaches (Corominas et al., 2014; Jaboyedoff et al., 2012; Metternicht et al., 2005).

Many studies have used multitemporal TLS (> month, defined by Eitel et al., 2016) to monitor landslide processes (Abellán et al., 2010; Avian et al., 2009; Bremer and Sass, 2012; Dewitte et al., 2008; Lague et al., 2013; Lato et al., 2014; Lim et al., 2005; Oppikofer et al., 2008; Rosser et al., 2005; Royán et al., 2015; Schürch et al., 2011; Teza et al., 2007; Travelletti et al., 2008); the use of TLS at a hypertemporal level (<month, defined by Eitel et al., 2016), however, is limited (e.g. Kromer et al., 2015a, b; Milan et al., 2007; Oppikofer et al., 2008). Additionally, monitoring at $>$ daily intervals, here defined as super-temporal monitoring, still represents a challenge and has yet to be exploited, especially over long-duration temporal monitoring periods. Fully 
utilizing the spatial $(x, y, z)$ and time dimensions in earth surface process studies represents one of the major growth areas of TLS research, as pointed out by the review paper by Eitel et al. (2016).

Studying earth processes at a super-temporal level with TLS has many possible advantages. It would reduce or eliminate the problem of event superposition and coalescence when monitoring geomorphic events too infrequently, as discussed in Lim et al. (2005). With frequent scanning measurement, uncertainties can be significantly reduced by taking advantage of the large number of spatial and temporal measurements collected (Abellán et al., 2009, 2013; Kromer et al., 2015b). Furthermore, in landslide emergencies, a TLS system would be highly beneficial as it can be easily transported, set up rapidly, and can be carried through rugged and remote areas. A TLS-based warning system would be a light, portable, cost-effective alternative to ground-based interferometric synthetic aperture radar (GB-InSAR) monitoring technologies.

The key challenges in using TLS to study earth processes at the super-temporal level is the high cost of frequent data acquisitions and challenges in processing and managing large numbers of data (Orem and Pelletier, 2015). The advent of automated terrestrial laser scanners (ATLSs) has made high-temporal-resolution terrestrial acquisitions easier (Adams et al., 2013; Eitel et al., 2013); however, automatic processing of the data is still required to relieve the post-processing burden. This is especially important for landslide early warning monitoring, where processed results are needed as soon as possible for decision makers.

The aim of this paper is to detail the development of an ATLS system with automatic near-real-time data processing and its application at a test landslide site. We demonstrate the feasibility and limitations of a near-real-time monitoring system and demonstrate how the system can be used to monitor pre-failure deformation of landslides and discrete rockfall events. The system may be suitable for a wide range of applications in the earth sciences, including monitoring of soil erosion, volcanic activity, fault movement and glacier dynamics, for example.

\section{Study site description}

We conducted our experiment at the Séchilienne landslide, located $20 \mathrm{~km}$ southeast of Grenoble in France along RD 1091 Grenoble-Briancon in the Romanche Valley of the French Alps (Fig. 1). This landslide was chosen for the experiment because its geological characteristics, movement, hydrology and hydrochemistry have been well studied (Baudement et al., 2013; Chanut et al., 2013; Dubois et al., 2014; Dunner et al., 2011; Guglielmi et al., 2002; Helmstetter and Garambois, 2010; Kasperski et al., 2010; Le Roux et al., 2011); existing infrastructure at the site made it ideal for testing the TLS system (Duranthon, 2006); and the variety of ac- tive slope processes, including displacement of the landslide, frequent rockfalls and movement of talus or scree material.

Kasperski et al. (2010) describe two parts of the landslide, an active frontal zone, known as "Les Ruines", and subsidence of the upper part of the Mont-Sec slope between 600 and $1180 \mathrm{~m}$ above sea level (a.s.l.) comprising an area of 70 ha, outlined in Fig. 1. The upper Mont-Sec slope is delimited by a 20 to $40 \mathrm{~m}$ high scarp (Helmstetter and Garambois, 2010). Over the past century the "Les Ruines" area has been a source of frequent rockfalls (Le Roux et al., 2011). Early studies of the landslide revealed the risk of collapse of 2 to 3 million $\mathrm{m}^{3}$ from the frontal zone and the instability encompassing Mont-Sec at around 20 to 30 million $\mathrm{m}^{3}$ (Evrard et al., 1990). More recent estimates of the landslide depth using geophysics put the frontal zone at 3 million $\mathrm{m}^{3}$ and the Mont-Sec instability at 60 million $\mathrm{m}^{3}$ (Le Roux et al., 2011). However, these volumes were established without precise knowledge of the slope deformation mechanism and are undoubtedly under-evaluated given the field data acquired since.

Geologically, the landslide is part of the external crystalline massif of Belledonne. The landslide mainly consists of mica schists, which are composed of alternating metamorphic sandstones and siltstones. Pothérat and Alfonsi (2001) identified several faults intersecting the landslide and three sets of near-vertical fractures: $\mathrm{N} 20^{\circ}, \mathrm{N} 120^{\circ}$ and $\mathrm{N} 70^{\circ}$. Detailed description of the geology of the landslide and surrounding area can be found in Helmstetter and Garambois (2010), Kasperski et al. (2010) and Le Roux et al. (2011).

The French public national body, Cerema, has been monitoring the landslide since 1985 (Dubois et al., 2014; Duranthon, 2006). Multiple monitoring techniques are used on the landslide including 31 extensometers, 30 radar targets, 65 infrared targets, and 2 boreholes with slope inclinometers and GPS receivers. A total station, a radar unit and a permanent camera station are located on the opposite side of the valley inside the Mont Falcon Station (shown in Fig. 3). Movement at depth is monitored using a $240 \mathrm{~m}$ long exploration adit and three $150 \mathrm{~m}$ depth boreholes in the high-motion zones. A seismic monitoring system has been in place since 2008 . The system consists of three seismological stations and receivers that record rockfall events and local- and regionalscale earthquakes (Helmstetter and Garambois, 2010).

Displacement of the landslide ranges from 0.01 to $0.10 \mathrm{~m}$ per year except at the level of the frontal zone in the east where displacements reach up to $3.5 \mathrm{~m}$ per year (Dubois et al., 2014). Figure 2 plots the displacement of extensometer A13 located in this frontal zone since 1994. Dubois et al. (2014) divided the landslide evolution into three main displacement phases:

- From 1994 to 2006, seasonal fluctuations of the displacement rates were observed in connection with precipitation (rain and snowmelt). 


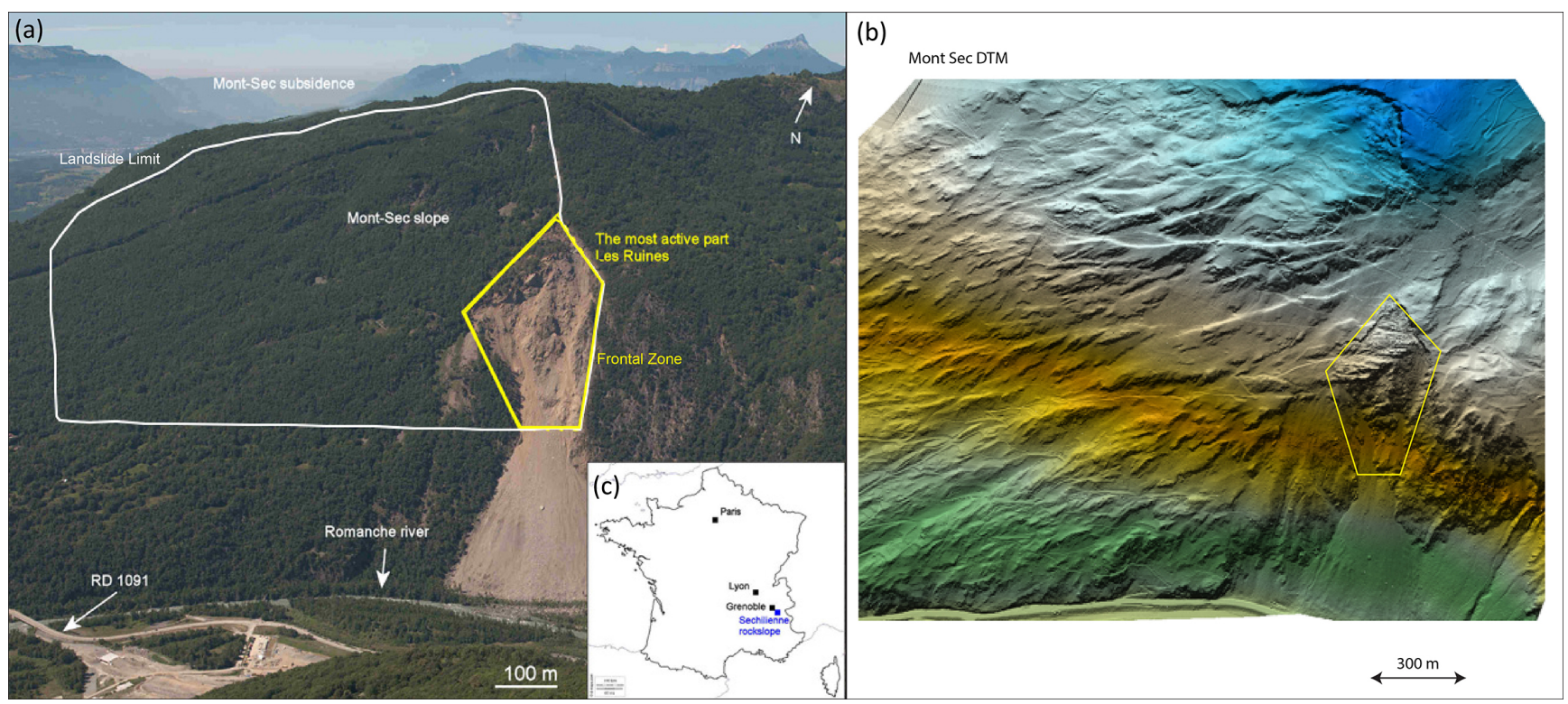

Figure 1. (a) Location of the Séchilienne rock slope in the Romanche River valley along RD 1091. The landslide is outlined in white covering an area known as the Mont-Sec slope. The most active frontal zone is outlined in yellow. (b) Digital terrain model (DTM) of the Mont-Sec slope with most active frontal zone of the landslide highlighted. (c) Location of the Séchilienne landslide within France.

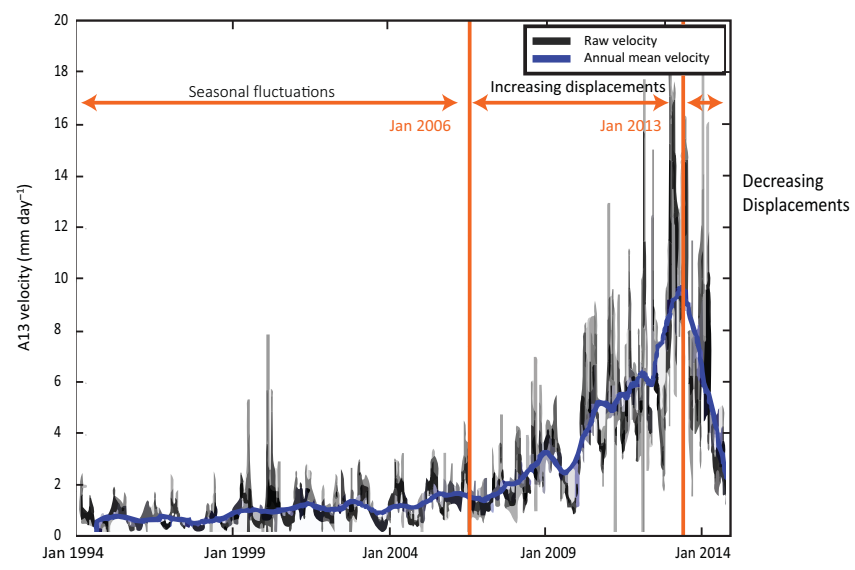

Figure 2. Velocity in $\mathrm{mm}$ day $^{-1}$ at extensometer A13 from 1 January 1994 until 31 March 2015 (black), and annual mean velocity (blue; Dubois et al., 2014).

- From 2006 to December 2012, there were less fluctuations of the displacement rates and a general increase of the average velocity.

- Since January 2013, a decrease in average velocity has been observed. This decrease has been strong since July 2013, then stronger since spring 2014. It has reached $-85 \%$ of peak velocity between end of June 2013 and end of July 2015.

Vallet et al. (2015) found that groundwater fluctuations explain the periodic variations in displacement and the longterm exponential trend, interpreted as a consequence of weakening of rock due to groundwater pressure action. The landslide shows signs of deep-seated gravitational deformation with displacement revealing a complex structure with cone sheet fractures, counterscarps, and depletion and accumulation zones. Kasperski et al. (2010) interpret a landslide failure mechanism of toppling and subsidence of vertical rock layers. Frequent measurements since 2009 support this interpretation revealing a deformation mechanism of deep flexural toppling without a basal failure plane.

In addition to the monitoring network, multi-temporal TLS (seven acquisitions between 2004 and 2009; Kasperski, 2008; and an additional five TLS scans from 2009 to 2015; Vulliez, 2016), multi-temporal aerial laser scanning (2011 and 2014) and terrestrial photogrammetry (2015) were conducted at the site (Vulliez, 2016). The goal of these data collections was to provide continuous spatial coverage of the landslide movement with a focus on the active frontal zone. The studies have helped characterize the instability and displacement patterns and have helped better elucidate the failure mechanism; however, prior to this study, high-spatialdensity hyper- and super-temporal data have not been acquired.

\section{Methods}

We designed the hardware components of the monitoring system described in Sect. 3.1 for the study of landslide, talus and rockfall processes at the Séchilienne landslide site. The hardware components were designed for a temporary (months) installation and took advantage of existing infras- 

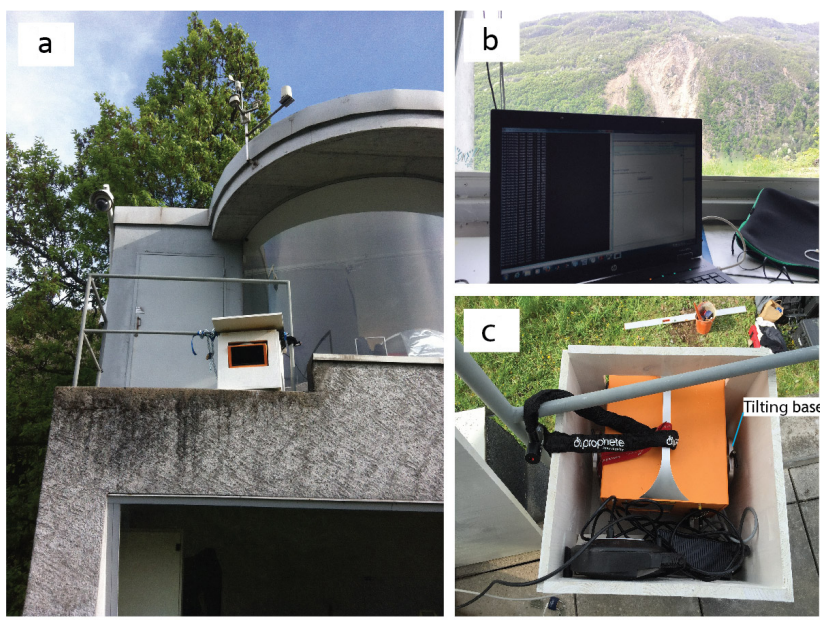

Figure 3. Setup of the ATLS monitoring system at the Cerema monitoring centre in Séchilienne, France, which consisted of (a) the TLS system and protective housing installed on the roof the centre; (b) a notebook installed inside the monitoring centre for near-realtime data processing and data visualization; and (c) TLS, tilting base and battery backup built within a protective housing.

tructure available at the study site, a concrete monitoring centre operated and maintained by Cerema. The hardware could be adapted for other use cases, for example a temporary monitoring installation in the order of days could be operated using a tripod and a generator, whereas a longerterm installation could be installed with a permanent protective housing, solar panels and batteries. The processing workflow described in Sect. 3.2 was designed to monitor earth surface processes in near-real time, defined as immediate post-processing after collection, taking less time than the time between scans. In this section, we point out design elements that are specific to the study of landslides and the TLS scanner used. For example, for the study of pre-failure deformation of rockfalls or landslide displacements, the timing of processing is critical to be able to provide timely warning of a potential imminent failure event and the workflow is designed to process data as quickly as possible after data collection. Specific input parameters pertinent to our study case and to landslide processes are described in Sect. 3.3.

\subsection{Site setup and hardware components}

We used an Optech ILRIS long-range (LR) laser scanner (Teledyne Optech, 2014a) for this study. We installed the TLS system on the roof of the monitoring centre (Fig. 3a). To protect the TLS system against the elements, we constructed a wooden encasement painted with a weather-resistant coating (Fig. 3c). The encasement housed the TLS, the battery backup, a manual tilt, power and Ethernet cables. We designed the front opening of the encasement so that it allowed $\pm 10^{\circ}$ of tilt but was still small enough to not allow the TLS to be removed. We opted for an open design compared to

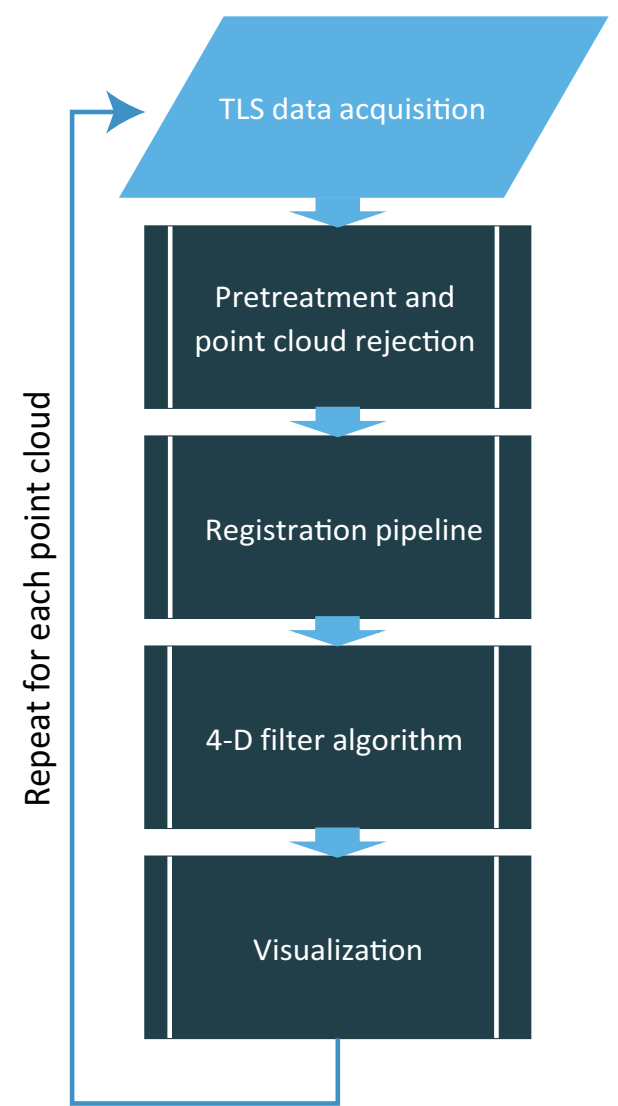

Figure 4. Near-real-time data processing workflow consisting of a data automated acquisition module, a pre-treatment and point cloud rejection stage, a rejection pipeline consisting of an initial alignment and an iterative fine alignment stage, a 4-D filtering and distance calculation algorithm (Kromer et al., 2015b) and a visualization module. This workflow is repeated for each point cloud acquisition.

one with an infrared permeable screen to maximize the intercepted returns and to allow natural ventilation of the equipment. Earlier testing through various glass mediums revealed interference with the signal return. To further increase ventilation, we included slits in both the side and back panels of the encasement. A lid covered the top of the encasement and extended in front of the viewing opening to minimize the amount of water entering the encasement. We bolted the encasement to the top of the monitoring centre structure and used chain and locks for theft protection. The TLS system was supplied with power via cables connected to the interior of the monitoring centre.

Data from the TLS system were transferred from the system to an on-site computer located in the interior of the monitoring centre (Fig. 3b). The purpose of the computer was for automated near-real-time data processing and visualization of the results. Data were stored on both the computer hard drive and on external backup drives. The computer consisted of an ordinary notebook (HP Elitebook 8740w) with a dual- 


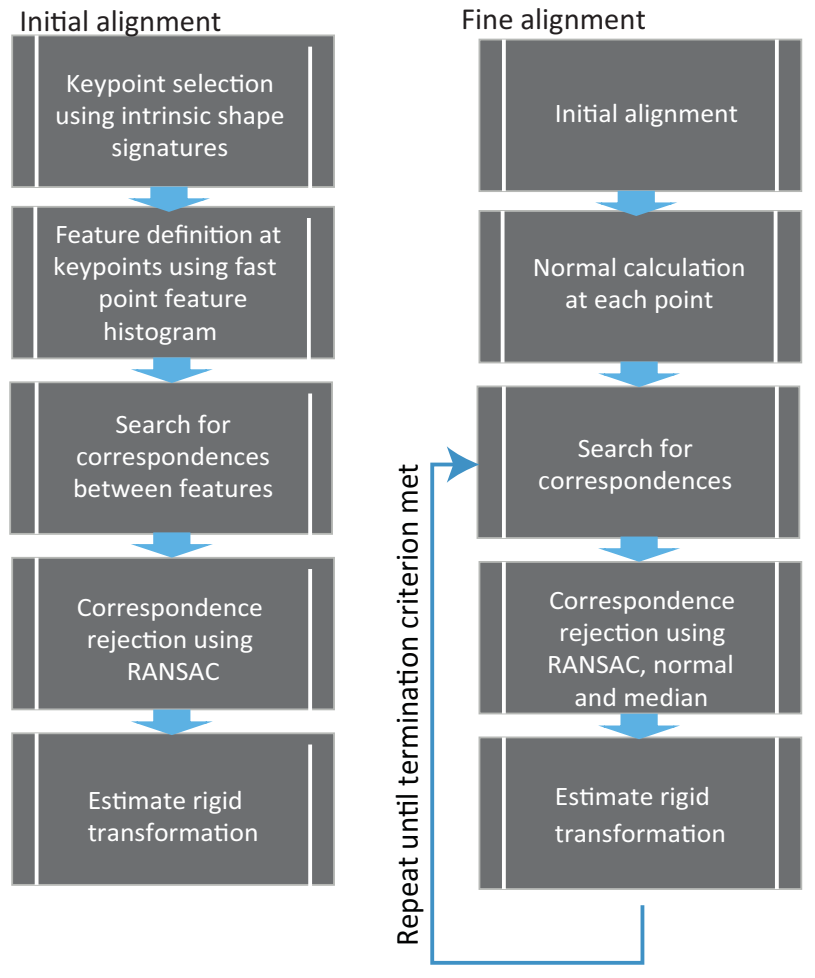

Figure 5. Registration pipeline workflow consisting of an initial alignment stage and a fine alignment stage. The initial alignment stage aligns two point clouds independent of orientation and position and is based on keypoint and descriptor matching. The fine alignment stage is an iterative corresponding point variant consisting of a matching, rejection and alignment stage.

core $2.67 \mathrm{GHz}$ Intel Core i7 processor and $4.0 \mathrm{~GB}$ of RAM. The computer was connected to the internet via a cellular link. This allowed the entire system to be operated and the data visualized remotely via remote control software.

\subsection{Processing workflow design}

Processing point clouds for change detection analysis typically involves several manual steps. These steps involve manually removing vegetation and erroneous points, picking similar points between successive point clouds for an initial estimation of the registration transformation matrix, an application of the iterative closest point (ICP) algorithm for alignment, the building of a meshed surface model and the calculation of distances (methods reviewed in Abellán et al., 2014). This manual process cannot be performed for scanners operating almost continuously and automation of these steps is required. Furthermore, the processing must happen rapidly so that the results can be interpreted in sufficient time in emergency scenarios, i.e. an impending landslide.

We designed the processing workflow of the system to operate the scanner at set intervals and to process the data in near-real time. The processing workflow consists of modules to operate the scanner automatically, to manage and back up data, and to automatically process the data. Due to intellectual property restrictions, we could not design our own module to operate the scanner; instead, we used Optech's ILRIS Command Line (ICL) application version 1.6.7 (Teledyne Optech, 2014b), which initiates a scan with predefined scan parameters. We designed a data processing module to intercept the incoming scan data from the ICL application. The data processing module was developed using $\mathrm{C}++$ with QT and the Point Cloud Library (PCL; Rusu and Cousins, 2011) and is outlined in Fig. 4. The first phase of the processing module consists of pre-processing steps: (a) removal of unwanted points using a pass-through filter and (b) a quality control (QC) step consisting of the rejection of a point cloud if it does not contain a specified minimum number of points, which is commonly due to poor atmospheric conditions or rainfall. This stage also applies an atmospheric correction to the point clouds. The second step is registration of the point cloud to a reference through a registration pipeline consisting of an initial alignment stage followed by an iterative fine alignment stage. The initial alignment stage was designed to align the point clouds if the scan position has been changed, but in general it is used as a good initial starting point to speed up the iterative registration process. The initial alignment consists of finding repeatable keypoints in the point cloud, defining descriptors based on the local keypoint point neighbourhoods and finding correspondences between features to perform an initial transformation. Refined alignment is conducted by iteratively transforming the point cloud, finding correspondences and using a rejector pipeline to discard poor correspondences until a convergence criterion is met (Fig. 5). Change detection is conducted by calculating slope-dependent change vectors and filtering noise using neighbours in space and time (Kromer et al., 2015b). The processed points clouds are visualized in near-real time using a visualizer designed using a PCL visualizing module, and change time series data are plotted using Matlab (The Mathworks Inc.). A detailed description of this workflow follows in Sect. 3.2.1 through 3.2.5.

\subsubsection{TLS data acquisition}

ILRIS 3-D scanners are typically operated through Optech's graphical controller software. To operate the scanner, the user manually defines a scan area as well as scan parameters such as optical camera setting, vertical and horizontal resolution, pulse interception (first or last) and the location to save the data. Before the data can be further processed, Optech's parser must be applied. All of the previous steps can be applied using Optech's ICL application (Teledyne Optech, 2014b). It is an executable program that reads a text file with pre-set scan parameters, runs the scanner once and outputs a ASCII-formatted point cloud ( $x, y, z$, intensity). We applied the ICL application using task scheduling software to make it operate the automated data collection task. Our processing 
workflow then monitored the output folder and intercepted the incoming point cloud for further processing.

The ICL application does not apply a proprietary process known as automated scan correction (ASC), which is part of the graphical controller software. This process is normally used to compensate range and angular measurements for temperature drift within the ILRIS itself (Wang and Lu, 2009). To compensate for the lack of ASC in the ICL application, we developed our own temperature correction process described in Sect. 3.2.2.

\subsubsection{Pre-treatment}

The first step in pre-treatment is the removal of unwanted points within the point cloud. Typical change detection workflows consist of the removal of vegetation points, removal of points outside the target and removal of outlier points (e.g. Abellán et al., 2014). In our workflow no specific algorithm for vegetation removal was applied because our test area was mostly clear of vegetation and we removed the effect of vegetation on point cloud registration through a rejection scheme (Sect. 3.2.3). By including vegetation, this also allowed us to monitor changes in vegetated areas on the slope, which can be important to study the effect of vegetation on rockfall triggering, for example (Krautblatter and Dikau, 2007), or used as a means to track the 3-D displacement of the landslide using object tracking methods (Monserrat and Crosetto, 2008; Oppikofer et al., 2009).

We applied two filters to the data, a statistical outlier removal and a pass through filter, available in the PCL filter class (Rusu and Cousins, 2011). The statistical outlier removal was used to remove areas with low point densities and sparse outliers, such as artefacts from multipath or edge effects (Lichti et al., 2005). By removing these points, errors in calculating surface normals, in registering the point cloud and in change detection are reduced. The outlier removal algorithm calculates for each point the distance to all its neighbours and removes points whose distances are outside of the point cloud's global mean and standard deviation. The pass through filter is used to remove points outside of a specified target area. For example, these may include points in the foreground or background or densely vegetated areas. This is done by defining limits in each dimension where points falling outside are to be removed.

The next pre-treatment step is querying the total number of points acquired in the point cloud. If the number of points does not meet a pre-defined threshold, the entire point cloud is rejected, no output is generated and the processing is queued until the next point cloud is intercepted. The purpose of this is to remove point clouds heavily affected by poor atmospheric conditions. These clouds suffer from low point density, are difficult to register and do not produce meaningful change detection results.

The last pre-treatment step consists of an atmosphere correction algorithm and was conceived due the restriction on
Optech's ASC mentioned in Sect. 3.2.1. This step was applied retroactively and has now been implemented into the system for automatic correction. Atmosphere corrections are applied as a scale factor and usually compensate for the varying speed of a laser at a given wavelength as it passes through varying refractions of air as a function of temperature, pressure, humidity, and $\mathrm{CO}_{2}$ content, e.g. Ciddor correction (Ciddor, 1996). Due to the lack of ASC, the internal system temperature drift had a larger effect on the range measurements than the refraction of the atmosphere, so we opted for a target-based correction. This correction may not be required for other scanner types that automatically apply this correction during data collection.

To conduct the atmosphere range correction, we used a network of pre-existing stable targets on the slope. The targets were measured independently using a total station during the monitoring period and showed non-significant displacement. We programmed the algorithm to automatically identify the targets based on the point cloud intensity values. The algorithm calculates the distances between the centroids of every target for the reference scan and for the target scan being corrected. The ratio of target distances of the reference scan and of the scan being corrected is then calculated. This ratio, or scale factor, was then applied to the point cloud being corrected. Application of this algorithm resulted in centimetre-level range corrections at the $1000 \mathrm{~m}$ range.

\subsubsection{Registration pipeline}

A registration pipeline is necessary since we cannot assume that the position and orientation of the scanner remains constant over time and because there are time-dependent measurement errors resulting from non-instrumental factors (e.g. environmental factors) that may not be accurately modelled. Even when a TLS scanner is in a fixed position, Lichti and Licht (2006) found there is a home position random bias which causes the measured position and orientation of the instrument to change over time. We found that repeated laser scanning, without moving the position of scanner, produced misaligned point clouds over different scan epochs. To decrease the overall processing time of the registration pipeline, we implemented an initial alignment stage. This provides that ICP algorithm with a better starting fit and consequently reduces the number of iterations required for convergence of the best-fit algorithm.

Time-dependent errors can also vary during a single data collection for slower scanners causing distortions of the scan. To reduce this effect, we opted to collect more frequent shorter scans so that the scans are taken with more consistent environmental conditions. To increase measurement certainty, we prefer to repeat point cloud acquisitions for this study design, rather than do repeated point measurements within the same scan, which results in point clouds that take longer to collect and are more affected by time-dependant errors. Our preference is for shorter scans to reduce distortions 
occurring within a scan in favour of errors in point cloud home position for scans collected at different epochs. The latter can be corrected using point cloud registration.

We designed our registration pipeline to consist of two main steps, an initial alignment stage and a fine alignment stage (Fig. 5), using the PCL registration application programming interface (API; Holz et al., 2015). The purpose of this design was to improve overall convergence time of the registration and to align clouds that are far apart, in cases where the scanner was moved, for example. In typical workflows the initial alignment stage involves manually selecting corresponding points between point clouds of successive epochs (e.g. Oppikofer et al., 2008). In our approach this is done automatically using descriptor matching (Holz et al., 2015).

The initial alignment step is performed using a subset of points known as keypoints. Keypoints consist of points in a point cloud that are both distinctive and repeatable. That is, they are unique points that can be found even if the point cloud was collected using different scanners or scan positions. To define these keypoints, we use the intrinsic shape signatures (ISS) algorithm (Zhong, 2009), which uses a pruning step to discard points with similar spreads along principal directions and includes points with large variations along each principal direction. At each keypoint we define feature descriptors using the fast point feature histogram algorithm (Rusu et al., 2009). For each keypoint, the relative orientation of normals and distances between all point pairs within a specified search radius are calculated. Correspondences are estimated between features in scans from difference epochs, using a nearest-neighbour search in feature space, using a fast approximate $k$-d tree neighbourhood search algorithm known as Fast Library for Approximate Nearest Neighbors (FLANN; Muja and Lowe, 2009). We use the Random Sample Consensus algorithm (RANSAC; Fischler and Bolles, 1981) to estimate the best rigid translation and rotation between the reference and data clouds completing the initial alignment. The idea of the initial alignment stage is to get the two point clouds close enough that the fine alignment algorithm converges quicker. The initial alignment stage can also successfully align points from different positions, e.g. if the scanner was moved or the orientation of the scanner changed. Parameters for the ISS pruning step, feature definition and RANSAC algorithm were empirically derived for our study case prior to the commencement of near-real time monitoring and can be found in the Supplement.

In the fine alignment stage, we use all the points in the point cloud as input to optimize the alignment. The correspondences are then trimmed down to include only stable areas using a rejection scheme. We designed our own iterative correspondence algorithm using the PCL registration API (Holz et al., 2015). The algorithm consists of an iterative process where we cycle through the following steps until a convergence criterion is met:

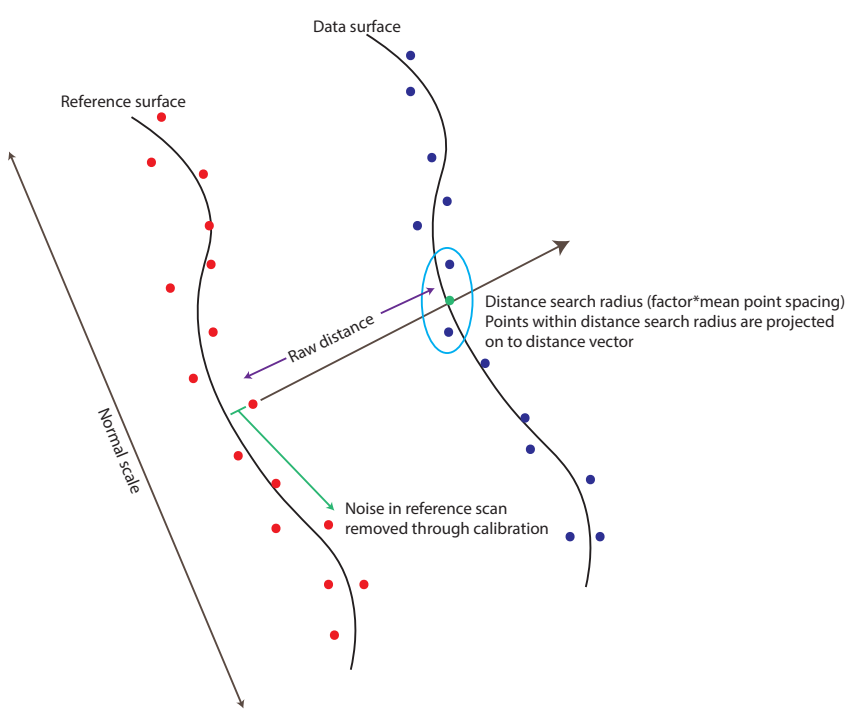

Figure 6. Drawing illustrating the distance calculation step. Raw distances are calculated along a local surface normal from the reference point. The corresponding point in the data cloud is calculated as the mean of the points projected on to the normal vector that are within a radius of a specified factor of mean point spacing.

1. Matching step $\rightarrow$ find correspondences between data and reference point clouds.

2. Rejection step $\rightarrow$ removal of invalid correspondences through a rejection pipeline.

3. Alignment $\rightarrow$ solve for the rigid transformation and rotation that minimizes the error of the correspondence pairs.

For the matching step, we find correspondences from points in the reference cloud to points in the data cloud using a normal shooting method (Chen and Medioni, 1992). We use a combination of correspondence rejection algorithms applied in series to filter out poor or erroneous matches. First we apply the RANSAC algorithm to eliminate outlier correspondences, as in the initial alignment step, followed by a surface normal filter and finally by a median rejector. The application of the RANSAC algorithm within the iterative framework keeps the algorithm from converging into a local minimum (Holz et al., 2015). The normal rejector filters out correspondences that have an incompatible normal and the median rejector filters out correspondences that are greater than a factor times the median for each iteration. It thus adapts during each iteration, becoming smaller as the point clouds become more closely aligned. In the alignment step, we find optimal rigid transformation by applying the Levenberg-Marquardt nonlinear solver (Levenberg, 1944; Marquardt, 1963) to minimize the error between the reference and data cloud using a point-to-plane error metric (Chen and Medioni, 1992). The three main steps - matching, rejection and alignment - are repeated until a predefined 
convergence/termination criterion is met. The convergence criteria consist of a maximum number of iteration absolute transformation threshold, a relative transformation threshold, maximum number of similar iterations, relative mean square error and absolute mean square error. Parameters for the ICP algorithm and rejectors applied in this study were empirically derived prior to monitored and can be found in the Supplement.

\subsubsection{Four-dimensional change detection and de-noising algorithm}

We use a four-dimensional (4-D; space and time) algorithm described in Kromer et al. (2015b) to detect change between successive point clouds and filter random noise due to surface roughness and instrumental error using neighbourhood distance values in both space and time. We apply an empirical calibration step to subtract systematic errors that are a result of using the same reference scan for all distance calculations from the reference scan (e.g. Fig. 6). Point cloud to point cloud distances are averaged using neighbourhood distance values in space and through time. A balance between spatial and temporal averaging should be optimized for the signal being studied, as discussed in Kromer et al. (2015a), to avoid spatial or temporal smoothing of the distance values. The combined total of spatial and temporal neighbours used for averaging also determines the reduction in uncertainty of the calculated mean distance values; for example, by averaging more distance samples in space and time, the uncertainty in the mean distance value will be reduced by a factor of (Eq. 1)

$$
\frac{1}{\sqrt{N N * T_{\text {step }}}},
$$

where $N N$ is the number of spatial neighbours used and $T_{\text {step }}$ is the number of temporal scans used for averaging.

The algorithm is described in detail in Kromer et al. (2015b). Here we summarize the main steps of the algorithms as they pertain to the near-real-time monitoring system. Each point cloud that is acquired first passes through the pre-treatment stage and registration pipeline. The initial point clouds collected are part of the calibration stage and this continues until the specified number of calibration point clouds is reached. Following the calibration phase, an accumulation phase begins. In this phase, points clouds are processed up until the number of point clouds used for temporal filtering is reached, defining the time step $\left(T_{\text {step }}\right)$. Once enough clouds have accumulated, temporal filtering begins. In this stage, for each point cloud, 4-D filtering is applied using the previous $T_{\text {step }}$ point clouds and the calibration distances are subtracted.

The 4-D algorithm calculates distances between point clouds using a slope-dependent normal, similar to that of the M3C2 algorithm described by Lague et al. (2013). Based on our experience with the system on a real slope in adverse atmospheric conditions, we made several minor changes to the 4-D algorithm's distance calculation step. In the distance calculation step described in Kromer et al. (2015b) we project a set number of points on to the local surface normal vector and take the average distance along the normal as the raw distance (Fig. 6). Here we added a limitation as to how far the points can be found away from the local surface normal vector. This limitation is a specified factor of the mean point spacing of the slope. For example, if set to a factor of 1.5, points outside 1.5 times the mean point spacing will not be projected on to the local normal vector for raw distance calculation. Additionally, to prevent averaging distances using spatial neighbours that are too distant from the target point, we apply a hybrid range and nearest-neighbour search. The hybrid approach firstly does a range search surrounding the target point, then checks whether the number of points found meets a minimum threshold. This threshold was set to (Eq. 2)

$$
\frac{1}{6} \pi R^{2}
$$

where $R$ is the range search radius. If the threshold is not met, a not-a-number $(\mathrm{NaN})$ value is assigned to the target point. With these modifications, the number of points used to calculate the raw distance and for spatial averaging and the distance uncertainty will be variable. The spatial variability in the uncertainty is calculated using the spatio-temporal confidence interval (Sect. 3.2.5).

\subsubsection{Spatio-temporal level of detection}

We define a spatio-temporal level of detection to account for errors that vary through space and time. Factors such as variable target distance (and thus footprint size), variable point density, incidence angle, variable reflectivity, atmospheric conditions and variable roughness all contribute to spatially variable errors on the slope (Lague et al., 2013). Additionally, changing atmospheric conditions, scanner temperature, slope reflectivity and misalignment errors can change through time.

Lague et al. (2013) estimated statistically significant change between two point clouds of a complex topography using a spatially variable confidence interval. We added the temporal component to the confidence interval because both spatial and temporal averaging is conducted in the 4-D algorithm. The spatial-temporal confidence interval is calculated at the $95 \%$ confidence level and represents an estimate of distance uncertainty for a specific point in space at a specific moment in time. As in Lague et al. (2013) and Fey and Wichmann (2017), we define the confidence interval at $95 \%$ or the level of detection at $95 \%\left(\mathrm{LoD}_{95} \%\right)$ to represent an estimate of the minimum detectable change.

To estimate the spatial-temporal confidence interval, we first calculate the distribution of distances using all the comparisons from the reference cloud to the calibration clouds 
(a)

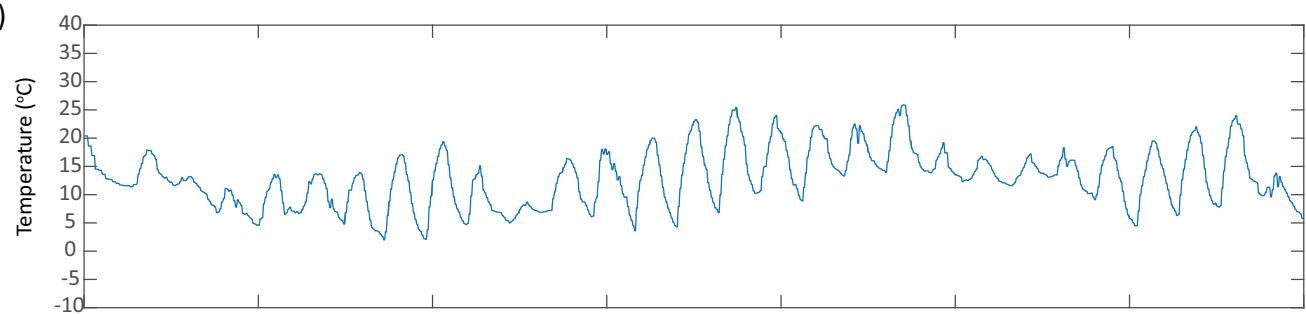

(b)

$1.04 \times 10^{5}$ 1.035 1.03 त. 1.025

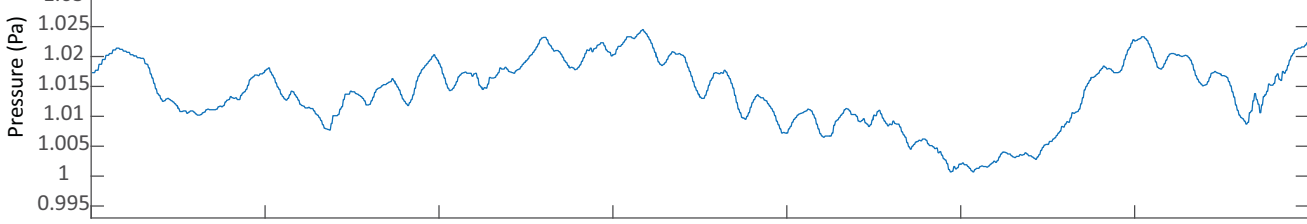

(c)

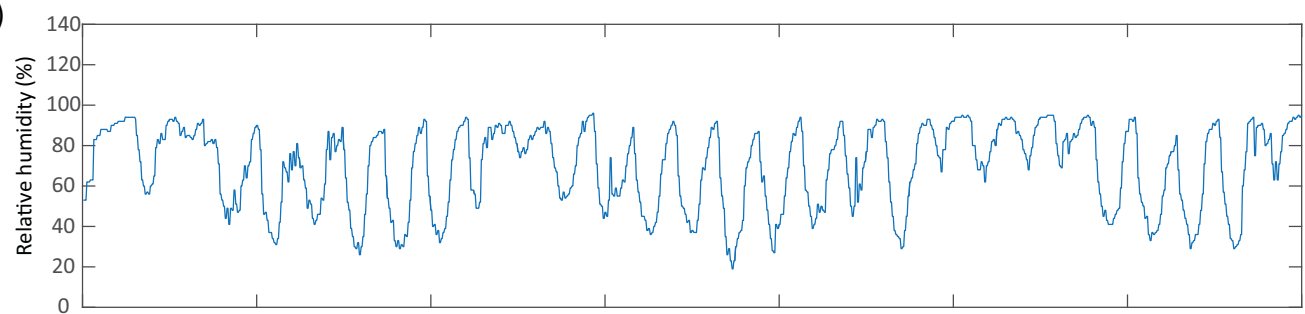

(d)

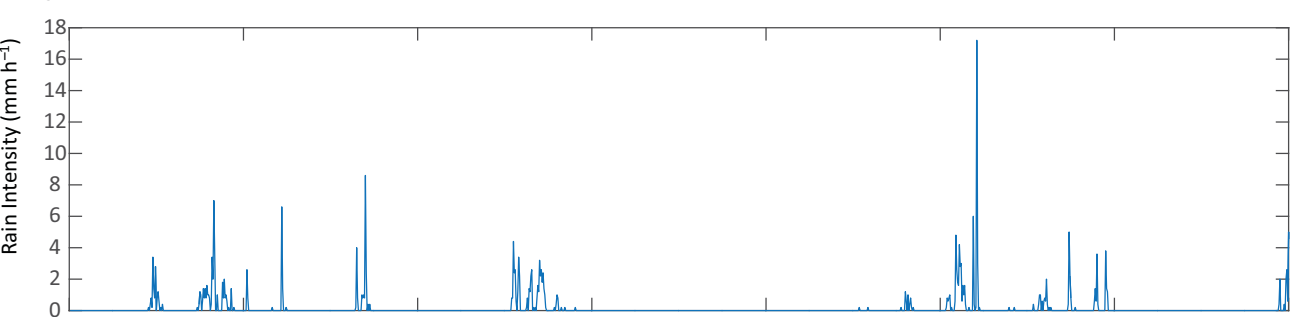

(e)

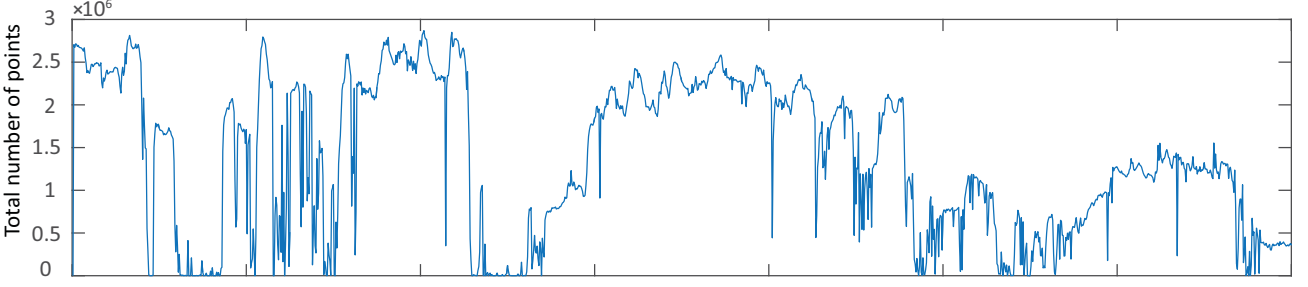

(f)

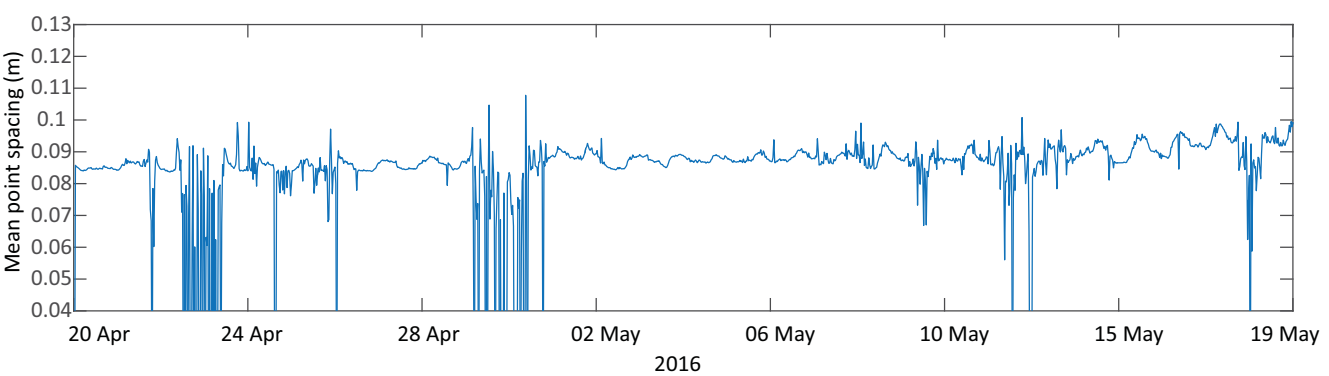

Figure 7. Graphs showing time series of environmental variables and of data quality. Comparison of temperature (a), pressure (b), relative humidity (c), rain intensity (d), total number of points (e) and mean point spacing of the total number of points (f) from 20 April to 20 May 2016. 
and the distribution of distances from the comparison of the reference cloud to all the data clouds within the specified temporal averaging window $\left(T_{\text {step }}\right)$. The two distributions, reference to calibration cloud distances and reference to $T_{\text {step }}$ cloud distances, are assumed to be two independent Gaussian distributions with independent variances, variances $\left(\sigma_{\text {cal }}, \sigma_{\text {data }}\right)$, as in Lague et al. (2013). The two distributions have means $\mu_{\mathrm{cal}}$ and $\mu_{\mathrm{data}}$ and have sizes of $n_{\mathrm{cal}}$ $(N N \times$ calibration clouds $)$ and $n_{\text {data }}\left(N N \times T_{\text {step }}\right)$, respectively. The confidence interval at $95 \%\left(Z_{\text {score }} 1.96\right)$ is then calculated using a $\mathrm{Z}$ test formulation for the difference between means $\mu_{\text {cal }}$ and $\mu_{\text {data }}$ for $n_{\text {cal }}$ and $n_{\text {data }}$ greater than 30 in Eq. (3).

$\operatorname{LoD}_{95 \%}= \pm 1.96\left(\sqrt{\frac{\sigma_{\text {cal }}^{2}}{n_{\text {cal }}}+\frac{\sigma_{\text {data }}^{2}}{n_{\text {data }}}}+\sigma_{\text {reg }}\right)$

To account for changing systematic errors, misalignment errors and remaining errors in the total error budget, we define an empirical registration term to the level of detection estimate as in Lague et al. (2013) and Fey and Wichmann (2017). This is estimated by calculating distancing using the 4-D algorithm at stable target and assumed stable locations on the slope. The standard deviation of the distance measurement is then used for the registration term in the level of detection calculation.

In our change detection design, positional uncertainties between the reference point cloud and the true slope surface are not propagated, as all subsequent scans are registered and compared to the reference scan. For this reason, we do not include a positional uncertainty term as in Fey and Wichmann (2017). Generally, for landslide and rockfall early warning monitoring, the absolute accuracy of the distance measurement is of less importance than being able to confidently detect whether displacement or changes in displacement have occurred.

\subsubsection{Data visualization}

We designed the monitoring system so that both RAW and processed point clouds can be visualized in the field or through a remote connection to the field computer. This was done to avoid large data transfer to a remote server and so results could be directly visualized and interpreted in the field. To support visualization and interpretation, we store point clouds with mapped raw distances, filtered distances and confidence intervals in point cloud libraries binary ped format. Because all distances are mapped onto the reference point cloud, we also stored all of the measured distances and confidence intervals over time in a database mapped to the index points of the reference point cloud. This allows time series of distances and confidence to be extracted by point picking on the slope. We programmed a basic point cloud visualizer using the PCL's visualization class (Rusu and Cousins, 2011). The visualizer can be initiated after each point cloud is processed. We used CloudCompare to visualize and create some of the figures in this paper.

\subsection{Monitoring experiment}

Our TLS system was set up to monitor the frontal zone of the landslide outlined in Fig. 1. This area is $200 \mathrm{~m}$ wide and $350 \mathrm{~m}$ high and is between 700 to $1200 \mathrm{~m}$ away from Cerema's monitoring centre on the opposite side of the river valley. Prior to our monitoring experiment, we sent the Optech TLS system for manufacturer maintenance and calibration to limit systematic errors. We intended to detect displacement of the landslide, pre-failure displacement to discrete rockfall events emanating from the frontal zone and talus processes. We opted for a $30 \mathrm{~min}$ data acquisition interval so that pre-failure deformation for discrete rockfall events could be recognized and to reduce event superposition. We collected a total of 1832 scans during from 20 April to 30 May 2016. Scanning was interrupted on 21 May as the scanner was moved and replaced for a period of 1 day.

We specified scanning parameters to obtain a mean point spacing of $0.08 \mathrm{~m}$ at the slope. We rejected point clouds acquired with fewer than 500000 points. In the 4-D change detection algorithm, we used a $3 \mathrm{~m}$ radius to calculate local surface normals, 5 times greater mean point spacing $(\sim 0.4 \mathrm{~m})$ than neighbourhood search radius and eight calibration and $T_{\text {step }}$ clouds ( $4 \mathrm{~h}$ period) for temporal filtering. We use these parameters because we expect to detect blocks that are much larger than the neighbourhood radius and with a lower limit of detectable displacement occurring over a longer period than the $T_{\text {step. }}$. Parameters specific to the point cloud pretreatment and registration were empirically derived for our case study and can be found in the Supplement.

We compiled temperature, pressure, and relative humidity data at $30 \mathrm{~min}$ intervals from a weather station located near Grenoble. Since the weather station was not located directly at our site, slight differences in local conditions are likely to have occurred.

\section{Results}

The system successfully ran automatically in near-real time for our study period. Data collection of the slope took approximately $7 \mathrm{~min}$, followed by $3 \mathrm{~min}$ of processing time. The Optech scanner collects data from bottom to top, meaning a delay of 3 to $10 \mathrm{~min}$ (top to bottom) occurred between data collection and visualization of the data. We moved and replaced the scanner once during the study and the processing algorithm successfully resumed operation despite the position change. In the following section we assess the data quality as a function of weather and atmospheric conditions (Sect. 4.1), the measurement and uncertainty over space and time (Sect. 4.2), and the observed slope processes (Sect. 4.3). 


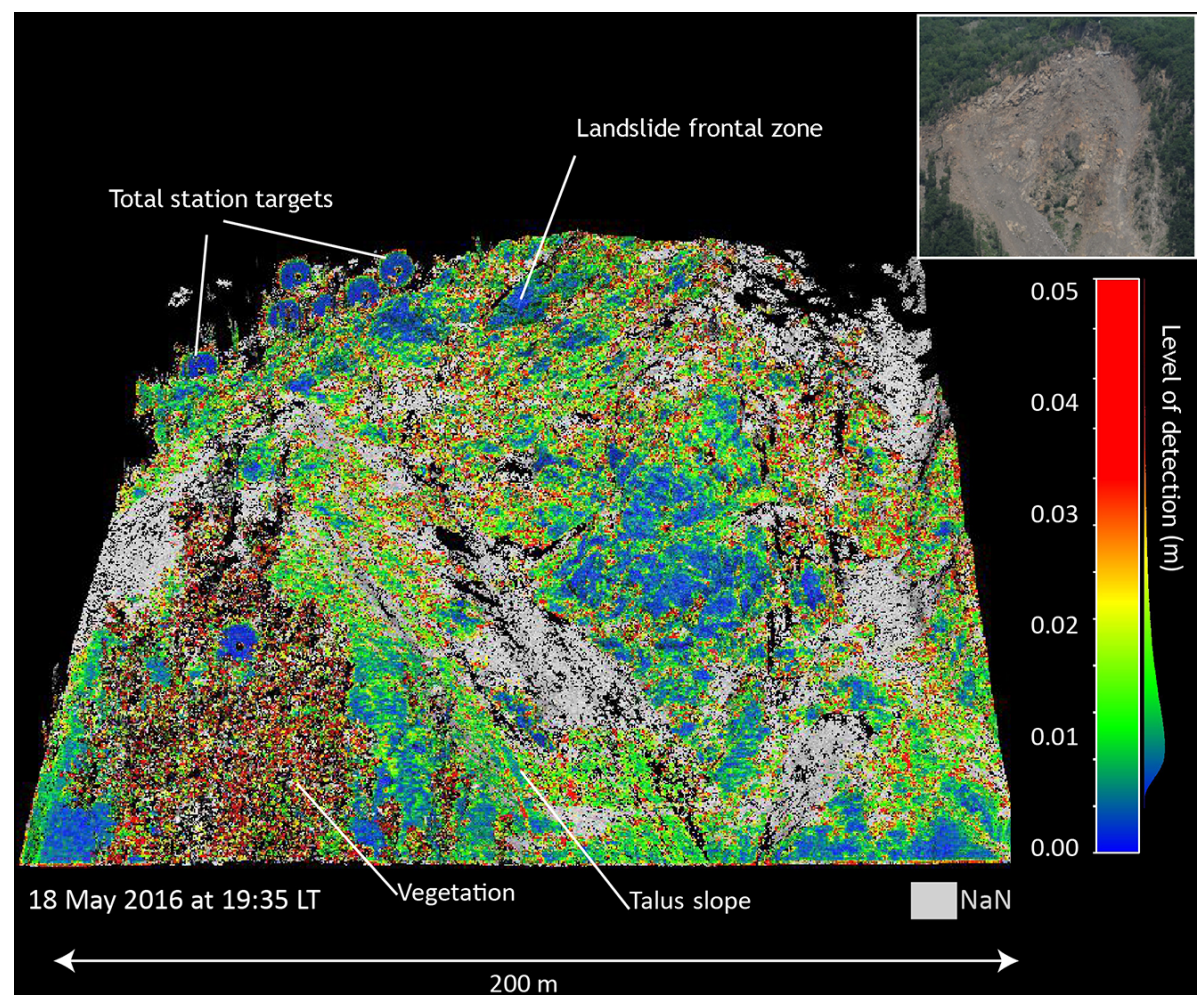

Figure 8. Variability in the spatio-temporal confidence interval in space for the most active area of the slope (Fig. 1). Level of detection mapped onto point clouds collected on 18 May 2016.

\subsection{Data quality}

Environmental influences had a noticeable effect on the data quality collected with our system. Because our test occurred during the spring season, the system scanned through a variety of atmospheric conditions. Recorded temperatures for the period ranged from 1.5 to $28.5^{\circ} \mathrm{C}$, relative humidity ranged from 19 to $96 \%$, and pressure ranged from 100070 to $102450 \mathrm{~Pa}$. These variables also fluctuated daily, as can be seen in Fig. 7a, b and c. These daily fluctuations are also reflected in the total number of points collected (Fig. 7e) and the mean point spacing (Fig. 7f). The daily cycles in temperature, pressure and humidity had a small influence on the data quality, accounting for daily differences of 200 to 300000 points and differences of mean point spacing ranging from 5 to $10 \mathrm{~mm}$.

Rainfall had a much more significant impact on the data quality than temperature, humidity and pressure. Several rainfall events occurred during the monitoring period (Fig. 7d). The most intense rain occurred on 11 May, reaching an intensity of $17 \mathrm{~mm} \mathrm{~h}^{-1}$. The effect of these rainfall events can be seen by comparing the intensity of rainfall versus the total number of points and mean point spacing. Independent of intensity, all recorded rainfall affected the number of points collected on the slope surface to the point where we rejected the point cloud from further analysis, i.e. having fewer than 500000 points. Following rain events, the time it took the total number of points to recover to pre-rainfall levels appears to depend on the intensity and duration of the rain period. This is likely the result of reduced reflectivity of the slope after rainfall. The mean point spacing, measured using the total number of slope points returned, recovered more quickly after rain events. This is because of the differing reflective properties of the slope material. Vertical rock slope material returned a similar amount of points before and after rain, thus having similar point spacing, whereas areas of talus and lower reflectivity areas did not register any returns. This effect can also be explained by the vertical portions of the slope drying faster than the lower angle portions. The quality of data acquired by other TLS systems with varying wavelengths may be less influenced by rainfall than the Optech ILRIS scanner utilized in this study.

\subsection{Assessment of uncertainty}

Our data processing pipeline was designed to reduce errors. The statistical outlier remover and the pass-through filter applied during the pre-treatment step successfully removed multipath errors, outlier points and areas of low point density. The filters also removed some of the vegetation, leaving repeated areas of vegetation with high point density (e.g. tree trunks and branches). 


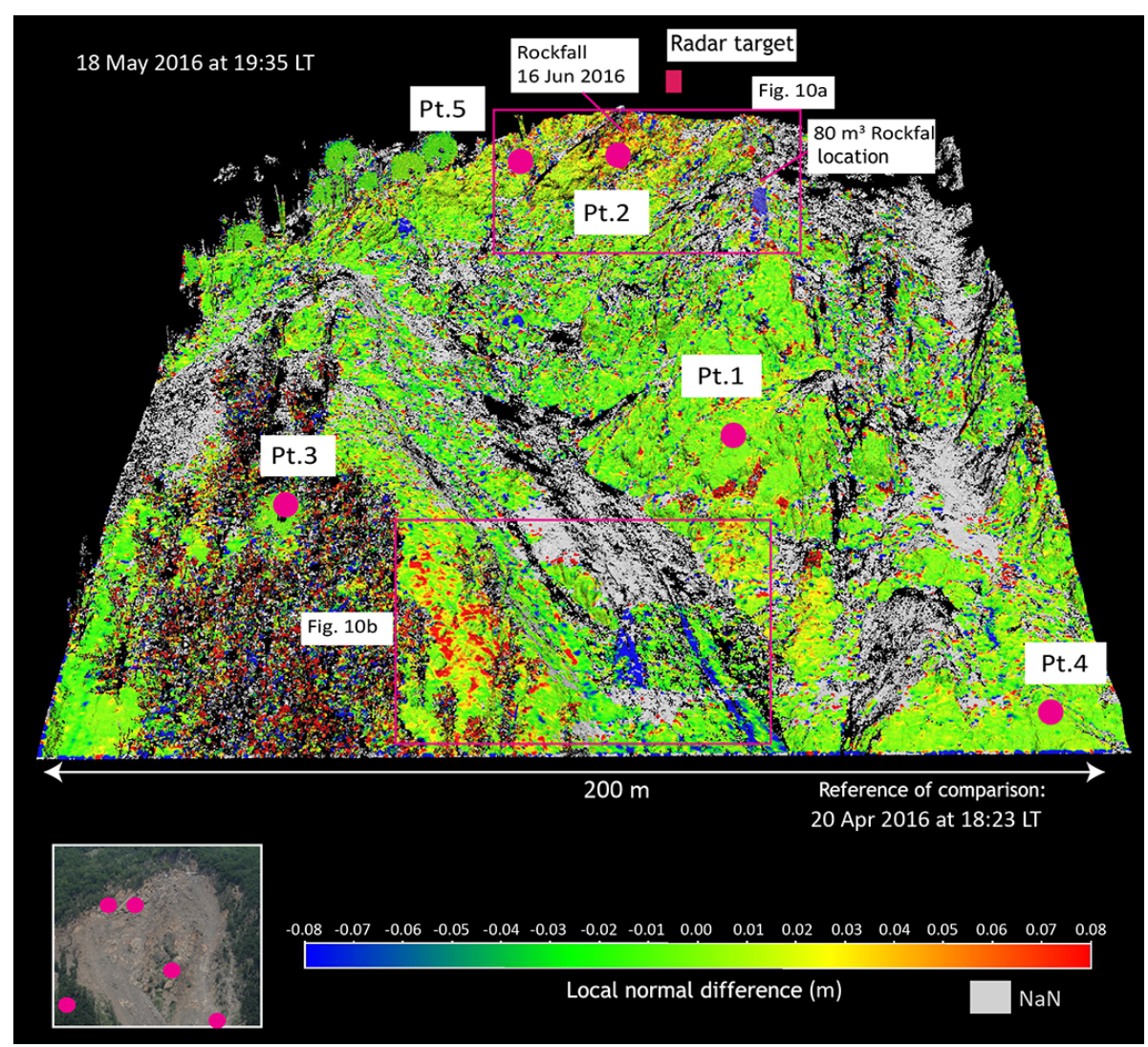

Figure 9. Change detection results for 18 May 2016 at 22:35 LT relative to a reference scan from 20 April 2016 at 18:23 LT. Five points of interest are marked and used to extract distance time series data and the location of two significant rockfall events are marked. Point 1 represents stable rock surface, Point 2 is located on the rock surface at the location of the rockfall on 16 Jun 2016 , Point 3 is located on a stable reflective target, Point 4 is located on debris slope and Point 5 is located on the frontal zone of the landslide.

We estimated distance uncertainty for every distance measure in every scan in terms of the level of detection. Figure 8 illustrates an example of the level of detection mapped on to the point cloud for data collected on 18 May 2016 at 19:35 LT. The level of detection varies for different areas of the slope and varies for different scan dates. Detection levels of 10 to $11 \mathrm{~mm}$ was achieved for vertical areas of the outcrop and the total station reflectors, whereas areas of outcrop with faces at a lower incident angle to the incoming laser pulse range from 15 to $20 \mathrm{~mm}$. Furthermore, detection levels of areas of talus slope and areas affected by vegetation ranged from 14 to $30 \mathrm{~mm}$. The empirical registration error term varied from 3 to 15 throughout the time series. Higher values of registration error and overall level of detection occurred during periods with adverse atmospheric conditions and during periods with diminished total returns. The diminished returns are likely contributing to a slightly different overall alignment and increase the uncertainty due to surface roughness. The level of detection over time as well as comparison with independent measurements is also presented alongside change detection results in Sect. 4.3 (Fig. 11).

\subsection{Observed slope processes}

During the testing period, we observed several slope processes including the flux of talus, movement of the rockslide and rockfalls coming from the rockslide surface. Figure 9 presents a change detection summary with five points of interest, the location of an $80 \mathrm{~m}^{3}$ rockfall event and the location of a second significant rockfall event that was detected by the microseismic system after the monitoring period on 16 June 2016. Point 1 is located on the lower frontal zone of the landslide, Point 2 is located in the western half of the upper frontal zone, Point 3 is in the lower part of the large landslide located on a total station reflector, Point 4 is a talus area east of the large landslide and Point 5 is located on the frontal zone of the landslide. For each of these points of interest, time series of distance and levels of detection are presented in Fig. 11.

Points 1, 3 and 4 show non-detectable levels of change during the monitoring period, which is consistent with monitoring data of the landslide. For Point 3, total station measurements during the time interval are presented alongside the TLS displacement results and deviations are less than the 


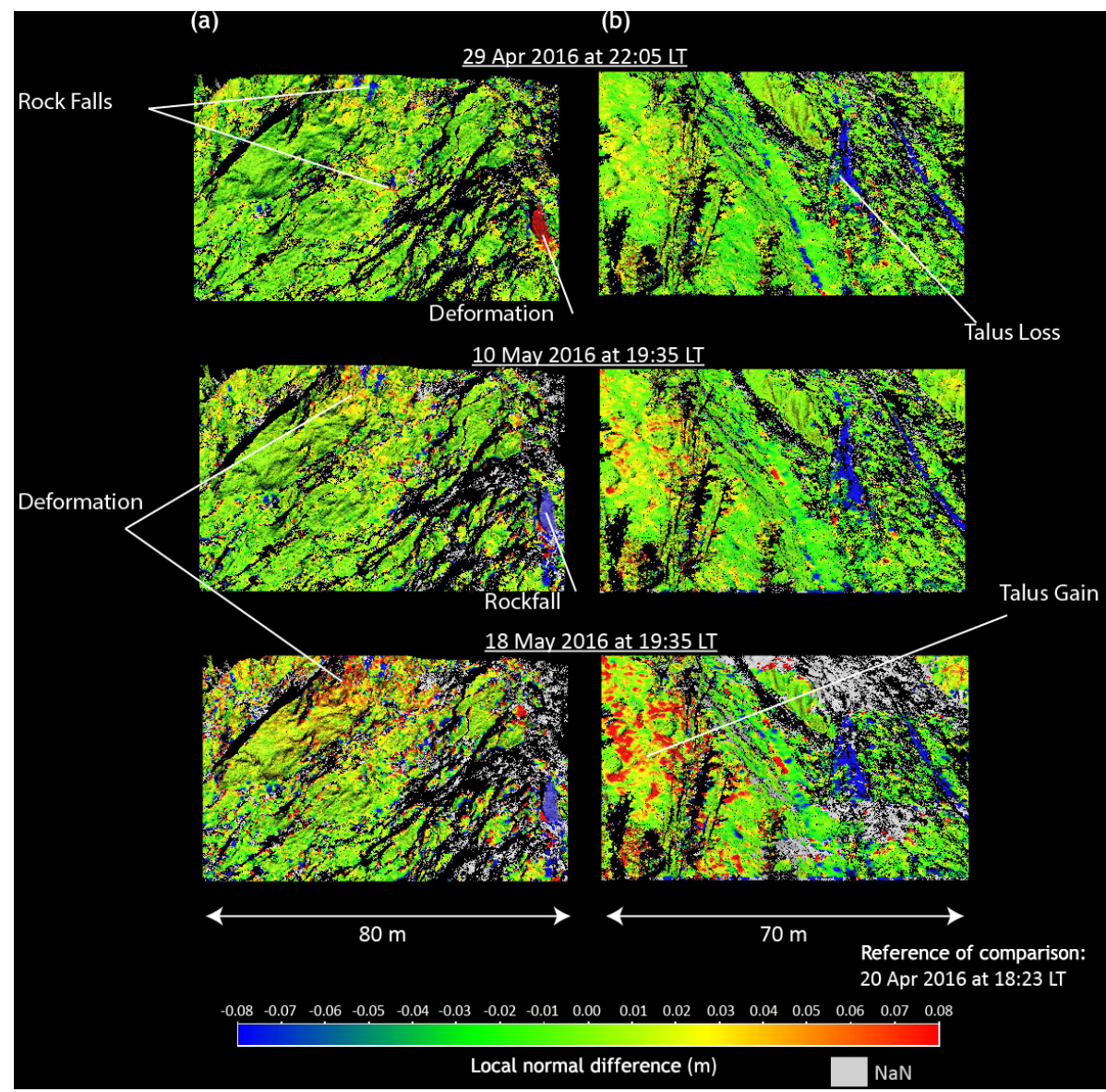

Figure 10. Change Detection results for three sub areas identified in Fig. 9 showing the flux of talus, deformation of the landslide and rockfalls.

calculated levels of detection. Periods of wet slope can be identified in the time series data by high level of detection values and inconsistent distance data, i.e. between 11 May and 16 May 2016. Periods of rain have affected these five areas by different amounts. Point 4 on the talus slope is most affected by the wet slope and Point 3 located on the total station reflector is least affected. Point 2 represents the landslide frontal zone displacement at a location where a second significant rockfall occurred on 16 June 2016. This rockfall was detected by the seismic network after the TLS monitoring period. Prior to failure, a constant rate of displacement was observed, reaching a maximum displacement of $0.11 \mathrm{~m}$. The displacement time series shows similar characteristics to a nearby radar station, which recorded a $0.05 \mathrm{~m}$ displacement over this interval. The radar target is located just outside of the TLS scan area and the physical separation of the two measurement points is likely the cause the maximum measured displacement discrepancy. Point 5 represents the displacement of the landslide frontal zone, reaching a maximum of $0.025 \mathrm{~m}$. This is in agreement with extensometer A16, which recorded a displacement of $0.023 \mathrm{~m}$ during the same period.
Apart from monitoring the displacement of the main landslide body, the system captured pre-failure deformation for specific rockfall events (Figs. 9 and 10). We identified and measured pre-failure deformation prior to an $80 \mathrm{~m}^{3}$ rockfall in the upper section of the monitored area. Figures 9 and 10 shows the location of the rockfall and Fig. 12 illustrates the deformation time series for three deforming points and one stable reference point. Data gaps in the time series represent time where point clouds were rejected due to insufficient points, i.e. during rain events. The rockfall was preceded by 6 days of deformation appearing to be triggered by the intense rain event on 23 and 24 April 2016 ( $39 \mathrm{~mm}$ in $31 \mathrm{~h})$. After the rain event, there was significant acceleration of the block over a $12 \mathrm{~h}$ period (with average velocities between 200 and $400 \mathrm{~mm} \mathrm{day}^{-1}$, from the bottom to the top of the block) followed by a constant rate of deformation (with average velocities between 15 and $30 \mathrm{~mm} \mathrm{day}^{-1}$, from the bottom to the top of the block, a relative decrease of $90 \%$ ). On 29 April 2016 a second acceleration (with average velocities between 150 and $260 \mathrm{~mm} \mathrm{day}^{-1}$, from the bottom to the top of the block) began, ending in sudden failure of the block on 30 April 2016 at 20:25 after a new rain event (12 $\mathrm{mm}$ in $6 \mathrm{~h}$ ). 


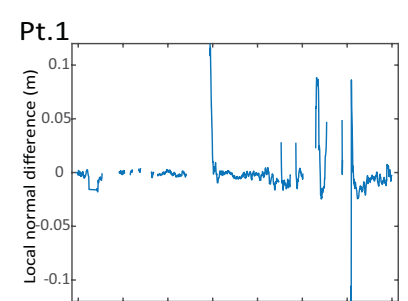

Pt. 2
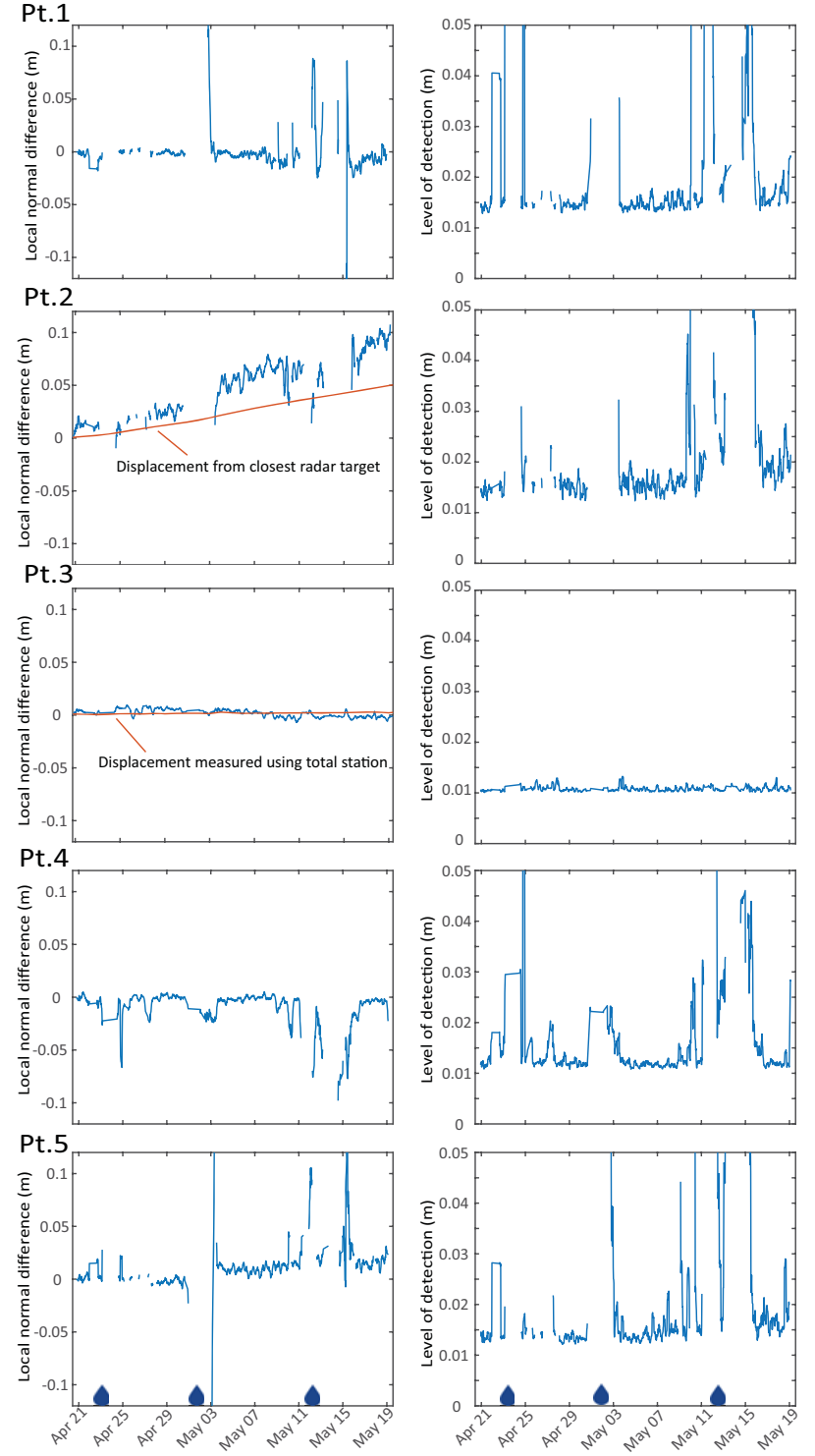

Figure 11. Distance and associated level of detection time series for points of interest 1 to 5 marked in Fig. 8. Point 1, 3 and 4 represent areas of the slope with non-detectable change. Point 2 represents the pre-failure deformation of a rockfall that occurred on the 16 June 2016 and Point 5 represents the deformation of the frontal zone of the landslide. Point 2 includes a comparison with measurements taken from the closest reference target and Point 3 includes a comparison with measurements taken with a total station for the same target area.

The exact time of the event was extracted from the microseismic system record of the rockfall event. The maximum total deformation of the block reached $0.30 \mathrm{~m}$ (Point 3 ) to $0.45 \mathrm{~m}$ (Point 1) prior to block detachment. The movement of the three points illustrated in Fig. 12 describes a local block toppling failure, characterized by larger deformation at the top of the unstable block and smaller at the bottom.

\section{Discussion}

We presented an automatic processing TLS monitoring system which we have deployed at an active landslide site. The system allows the study of earth surface processes at unprecedented levels of temporal detail and opens the door for studying processes at the super-temporal level (multiple acquisitions per day) for long time intervals. The system is well suited for landslide and rock slope deformation monitoring and early warning systems and can also be adapted to study many other earth surface processes. The automated scanning and automatic processing requires little input from users and provides processed results in near-real time. This is of great benefit to decision makers in early warning scenarios, where time is an important resource.

For early warning monitoring the system can be a costeffective, small and portable alternative to GB-InSAR systems. It also offers significant spatial and temporal detail of other slope processes allowing the calculation of volumes and vector deformation (Abellán et al., 2009; Oppikofer et al., 2009). TLS systems also have the benefit of being easy to transport and set up. For temporary early warning monitoring scenarios, such as remediation of a rockslide along a transportation corridor, for example, TLS can be set up quickly using a portable power source (generators or batteries) and allow for results to be available directly on site without the need to transfer data to a remote server. This is especially beneficial in remote areas with no communication infrastructure, which is often the case in remote mountainous areas. The scanner can also be moved and resume scanning at a later date, unlike GB-InSAR, which suffers from phase decorrelation.

We achieved a distance uncertainty range of 10 to $11 \mathrm{~mm}$ for rock sections of the slope during favourable weather conditions, an improvement compared to an uncertainty of $25 \mathrm{~mm}$ achieved by Kasperski et al. (2010) at this study site using a Riegl LMS Z420i TLS. We did not achieve theoretical improvement in our ability to detect change using 4-D filtering as discussed in Kromer et al. (2015). The critical factor is changing systematic errors over time caused by a combination of influences such as atmospheric conditions, internal heating of the scanner and misalignment errors. Misalignment errors varied over time and were observed to be higher where total number of returns were reduced due to poor atmospheric conditions. Improvements to the detection levels achieved here could be reached by using scanners with wavelengths less affected by atmospheric conditions and by using a TLS system with a built-in scanner temperature correction. A survey design where a scanner is closer to the target of interest would also improve detection levels. Furthermore, alternative registration strategies may offer an improvement to the registration error term, for example the stable area detection registration algorithm proposed by Wujanz et al. (2016). For the observed phenomena at this site, however, a millimetre level of detection was not necessary over the $30 \mathrm{~min}$ 


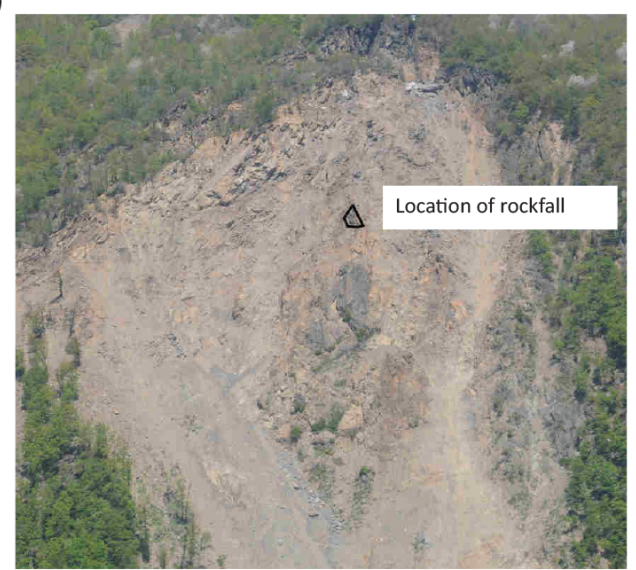

(c)

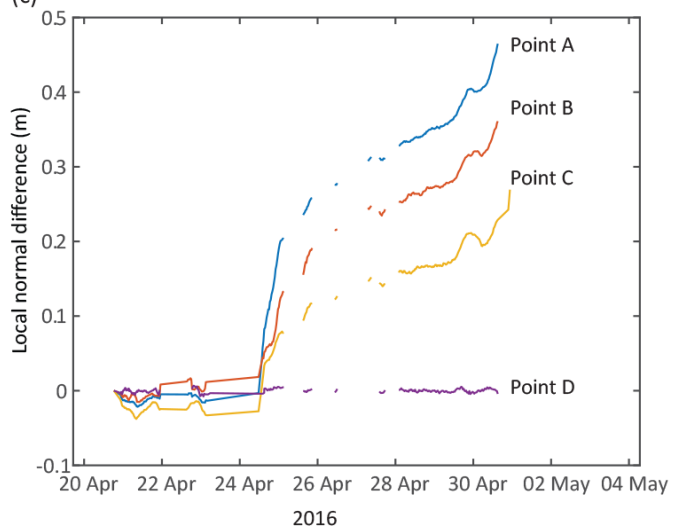

(b)

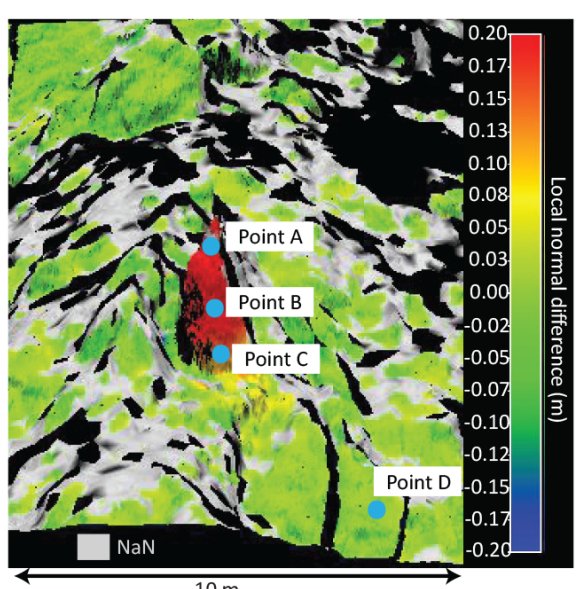

(d) 8

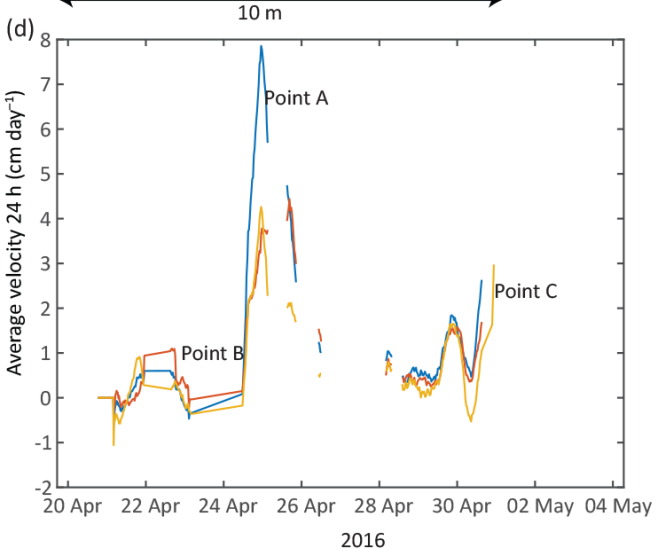

Figure 12. Pre-failure deformation of $80 \mathrm{~m}^{3}$ rockfall. (a) Location of $80 \mathrm{~m}^{3}$ rockfall. (b) Point cloud with mapped change showing deformation of the rock block prior to failure and four points used to plot time series data. Points A, B and C are located on the deforming area and Point D is located on an adjacent stable area of slope. (c) Deformation time series (cumulative values) of three points on the surface of the deforming rock block and a nearby stable point. (d) Average $24 \mathrm{~h}$ velocity for Points A, B and C.

intra-scan interval. The observed pre-failure deformation for the discrete rockfall event, for example, exhibited centimetre levels of displacement prior to failure and the displacement of the landslide was in the centimetre range over the study's time interval.

Atmospheric conditions including rain and changing surface reflectivity levels had a significant impact on the quality of data collected using the Optech long-range TLS with a $1064 \mathrm{~nm}$ wavelength. At this study site, the missing data points caused by rain did not significantly affect our interpretation of slope processes. Displacement of the landslide occurred over a longer temporal scale and small data gaps had a low impact on our ability to interpret slope deformations. Furthermore, displacement of the landslide tended to be delayed after rainfall. This effect has been observed by previous studies at this site (Helmstetter and Garambois, 2010; Vallet et al., 2015) and is believed to be due to the time it takes water to infiltrate and build pressure in the subsurface. For the case of the pre-failure deformation of the rockfall, the missed data points also did not affect the interpretation of the pre-failure stage.
This system was effective in monitoring the deformation of a deep-seated landslide automatically over a 6-week period of time. The detected deformation pattern in this case, greater movement at the top of the frontal zone compared to the bottom, is in agreement with the hypothesis of a toppling failure mechanism towards the valley (Kasperski et al., 2010b). The system was also successful in detecting prefailure deformation of an $80 \mathrm{~m}^{3}$ rockfall event and of a significant rockfall event that occurred after the monitoring period on 16 June 2016 from the frontal zone. The former rockfall appears to have been triggered by the rain episode from 22 April to 24 April 2016 and showed multiple acceleration phases before collapse. The period over which deformation occurred was only 6 days and may not have been captured using multi-temporal monitoring. A potential limitation of long-term monitoring with TLS is the limited operational life of the laser, which is not reported by the manufacturers of laser scanners.

We showed that this system can be beneficial for long-term monitoring of a landslide and for detecting the pre-failure stage of rockfalls. Although this study was applied to a land- 
slide site, the system developed herein can be adapted for wider applications for earth and ecological sciences, as discussed in Eitler et al. (2016). This system will allow the understanding, modelling and prediction of previously imperceptible earth changes.

\section{Conclusions}

In this study, we presented a near-real-time terrestrial laser scanner monitoring system that was tested on an active landslide in the French Alps. The system was designed to collect data in an automated fashion and process data automatically in near-real time. The system was tested for a 6-week period and captured flux of talus, displacement of the landslide, pre-failure deformation of rockfalls including 6 days of pre-failure deformation prior to an $80 \mathrm{~m}^{3}$ event. We were also able to assess the effect of environmental influences on data quality obtained with our scanner and defined a spatiotemporal confidence interval to estimate the variability in point cloud distance measurement uncertainty in space and time.

We found that the TLS system can be an effective tool in monitoring landslides and rockfall processes despite some of its limitations. These include missing points due to poor atmospheric conditions and changing slope reflectivity levels. At this study site, we observed slope deformation occurring over a longer period compared to the duration of the rain events and that there appeared to be a delay between the rain event and onset of increased slope deformation. For early warning monitoring of landslides, we showed that the system can be a suitable alternative to GB-InSAR deformation monitoring. The benefit of using this TLS system for landslide monitoring is that it can be easily transported, set up quickly, a portable power source can be used, data can be processed in remote areas in the field automatically and results would be made available in near-real time for on-site decision makers. Most importantly, we showed that TLS can be an effective system for long-term high-temporal-resolution acquisitions. The system solves the problem of manually managing and processing large numbers of TLS data and opens the door to future study of earth processes at high levels of temporal detail. Future use of high-temporal-resolution TLS monitoring of earth surface processes will greatly increase our understanding of previously imperceptible levels of earth change.

Data availability. The raw data can be requested from the Groupe Risque Rocheux et Mouvements de Sols (RRMS), Cerema CentreEst, France.

\section{The Supplement related to this article is available online} at doi:10.5194/esurf-5-293-2017-supplement.
Competing interests. The authors declare that they have no conflict of interest.

Acknowledgements. We would like to acknowledge the Centre for studies and expertise on Risks, Environment, Mobility, and Urban and Country (Cerema) for supporting the research. The first author would like to acknowledge support from the Natural Sciences and Engineering Research Council of Canada (NSERC) through the post-graduate scholarship programme. The second author would like to acknowledge the support received from the H2020 Program of the European Commission under the Marie Skłodowska-Curie Individual Fellowships (MSCA-IF-2015705215). We would also like to acknowledge Nick Rosser for helpful advice on atmospheric correction and Antoine Guerin for help with field data collection.

Edited by: A. Eltner

Reviewed by: R. Salvini and one anonymous referee

\section{References}

Abellán, A., Jaboyedoff, M., Oppikofer, T., and Vilaplana, J. M.: Detection of millimetric deformation using a terrestrial laser scanner: experiment and application to a rockfall event, Nat. Hazards Earth Syst. Sci., 9, 365-372, doi:10.5194/nhess-9-3652009, 2009.

Abellán, A., Calvet, J., Vilaplana, J. M., and Blanchard, J.: Detection and spatial prediction of rockfalls by means of terrestrial laser scanner monitoring, Geomorphology, 119, 162-171, doi:10.1016/j.geomorph.2010.03.016, 2010.

Abellán, A., Carrea, D., Jaboyedoff, M., and Royan, M. J.: LiDAR point cloud comparison: evaluation of denoising techniques using 3D moving windows, in: EGU General Assembly - Geophysical Research Abstracts, 15, p. 11884, 2013.

Abellán, A., Oppikofer, T., Jaboyedoff, M., Rosser, N. J., Lim, M., and Lato, M. J.: Terrestrial laser scanning of rock slope instabilities, Earth Surf. Process. Landforms, 39, 80-97, doi:10.1002/esp.3493, 2014.

Adams, M., Gleirscher, E., and Gigele, T.: Automated Terrestrial Laser Scanner measurements of small-scale snow avalanches, Proc. Intern. Snow Science Workshop Grenoble-Chamonix MontBlanc, 2013.

Avian, M., Kellerer-Pirklbauer, A., and Bauer, A.: LiDAR for monitoring mass movements in permafrost environments at the cirque Hinteres Langtal, Austria, between 2000 and 2008, Nat. Hazards Earth Syst. Sci., 9, 1087-1094, doi:10.5194/nhess-9-1087-2009, 2009.

Barbarella, M.: Monitoring of large landslides by Terrestrial Laser Scanning techniques: field data collection and processing, EuJRS, 126-151, doi:10.5721/EuJRS20134608, 2013.

Baudement, C., Bertrand, C., Guglielmi, Y., Viseur, S., Vallet, A. and Cappa, F.: Quantification de la dégradation mécanique et chimique d'un versant instable: approche géologique, hydromécanique et hydrochimique Etude du versant instable de Séchilienne, Isère (38), JAG-3èmes journées Aléas Gravitaires, 1-6, 2013. 
Bremer, M. and Sass, O.: Combining airborne and terrestrial laser scanning for quantifying erosion and deposition by a debris flow event, Geomorphology, 138, 49-60, doi:10.1016/j.geomorph.2011.08.024, 2012.

Chanut, M.-A., Dubois, L., Duranthon, J.-P., and Durville, J.-L.: Mouvement de versant de Séchilienne : relations entre précipitations et déplacements, Tunisie, 14-16, 2013.

Chen, Y. and Medioni, G.: Object modelling by registration of multiple range images, Image Vision Comput., 10, 145-155, doi:10.1016/0262-8856(92)90066-C, 1992.

Ciddor, P. E.: Refractive index of air: new equations for the visible and near infrared, Appl. Opt., 35, 1566-1573, doi:10.1364/AO.35.001566, 1996.

Corominas, J., van Westen, C., Frattini, P., Cascini, L., Malet, J. P., Fotopoulou, S., Catani, F., Van Den Eeckhaut, M., Mavrouli, O., Agliardi, F., Pitilakis, K., Winter, M. G., Pastor, M., Ferlisi, S., Tofani, V., Hervás, J., and Smith, J. T.: Recommendations for the quantitative analysis of landslide risk, B. Eng. Geol. Environ., 73, 209-263, doi:10.1007/s10064-013-0538-8, 2014.

Dewitte, O., Jasselette, J. C., Cornet, Y., Van Den Eeckhaut, M., Collignon, A., Poesen, J., and Demoulin, A.: Tracking landslide displacements by multi-temporal DTMs: A combined aerial stereophotogrammetric and LIDAR approach in western Belgium, Eng. Geol., 99, 11-22, doi:10.1016/j.enggeo.2008.02.006, 2008.

Dubois, L., chanut, M.-A., and Duranthon, J.-P.: Amélioration continue des dispositifs d'auscultation et de surveillance intégrés dans le suivi du versant instable des Ruines de Séchilienne, Géologue, 183, 50-55, 2014.

Dunner, C., Klein, E., and Bigarre, P.: Monitoring multi-paramètres du mouvement de versant des Ruines de Séchilienne (Isère, 38), Journées “Aléa gravitaire"(JAG 2011), 2011.

Duranthon, J. P.: Le mouvement de versant rocheux de grande ampleur des Ruines de Séchilienne-Surveillance Instrumentation, Journées Nationales de Géotechnique et Géologie de l'ingénieur (JNGG), 2006.

Eitel, J. U. H., Vierling, L. A., and Magney, T. S.: A lightweight, low cost autonomously operating terrestrial laser scanner for quantifying and monitoring ecosystem structural dynamics, Agr. Forest Meteorol., 180, 86-96, doi:10.1016/j.agrformet.2013.05.012, 2013.

Eitel, J. U. H., Höfle, B., Vierling, L. A., Abellán, A., Asner, G. P., Deems, J. S., Glennie, C. L., Joerg, P. C., LeWinter, A. L., Magney, T. S., Mandlburger, G., Morton, D. C., Müller, J., and Vierling, K. T.: Beyond 3-D: The new spectrum of lidar applications for earth and ecological sciences, Remote Sens. Environ., 186, 372-392, doi:10.1016/j.rse.2016.08.018, 2016.

Evrard, H., Gouin, T., Benoit, A., and Duranthon Séchilienne, J.-P.: Risques majeurs d'éboulements en masse: Point sur la surveillance du site, Bull. Liaison Lab. Ponts Chaussees, 165, 7-16, 1990.

Fey, C. and Wichmann, V.: Long-range terrestrial laser scanning for geomorphological change detection in alpine terrainhandling uncertainties, Earth Surf. Proc. Land., 4, 789-802, doi:10.1002/esp.4022, 2017.

Fischler, M. A. and Bolles, R. C.: Random sample consensus: a paradigm for model fitting with applications to image analysis and automated cartography, Communications of the ACM, 24, 381-395, doi:10.1145/358669.358692, 1981.
Guglielmi, Y., Vengeon, J., Bertrand, C., Mudry, J., Follacci, J., and Giraud, A.: Hydrogeochemistry: an investigation tool to evaluate infiltration into large moving rock masses (case study of $\mathrm{La}$ Clapière and Séchilienne alpine landslides), B. Eng. Geol. Environ., 61, 311-324, doi:10.1007/s10064-001-0144-z, 2002.

Helmstetter, A. and Garambois, S.: Seismic monitoring of Séchilienne rockslide (French Alps): Analysis of seismic signals and their correlation with rainfalls, J. Geophys. Res.-Earth, 115, 115, doi:10.1029/2009JF001532, 2010.

Holz, D., Ichim, A. E., Tombari, F., Rusu, R. B., and Behnke, S.: Registration with the Point Cloud Library A Modular Framework for Aligning in 3-D?, The Royal Society, 22, 110-124, 2015.

Jaboyedoff, M., Oppikofer, T., Abellán, A., Derron, M.-H., Loye, A., Metzger, R., and Pedrazzini, A.: Use of LIDAR in landslide investigations: a review, Nat Hazards, 61, 5-28, doi:10.1007/s11069-010-9634-2, 2012.

Kasperski, J.: Confrontation des données de terrain et de l'imagerie multi-sources pour la compréhension de la dynamique des mouvements de versants, Université Claude Bernard - Lyon I, Lyon, 8 February, 2008.

Kasperski, J., Delacourt, C., Allemand, P., Potherat, P., Jaud, M., and Varrel, E.: Application of a Terrestrial Laser Scanner (TLS) to the Study of the Séchilienne Landslide (Isère, France), Remote Sensing 2011, 2, 2785-2802, doi:10.3390/rs122785, 2010.

Krautblatter, M. and Dikau, R.: Towards a uniform concept for the comparison and extrapolation of rockwall retreat and rockfall supply, Geografiska Annaler: Series A, Phys. Geogr., 89, 21-40, doi:10.1111/j.1468-0459.2007.00305.x, 2007.

Kromer, R. A., Hutchinson, D. J., Lato, M. J., Gauthier, D., and Edwards, T.: Identifying rock slope failure precursors using LiDAR for transportation corridor hazard management, Eng. Geol., 195, 93-103, doi:10.1016/j.enggeo.2015.05.012, 2015a.

Kromer, R., Abellán, A., Hutchinson, D., Lato, M., Edwards, T., and Jaboyedoff, M.: A 4D Filtering and Calibration Technique for Small-Scale Point Cloud Change Detection with a Terrestrial Laser Scanner, Remote Sensing 2011, 7, 13029-13052, 2015b.

Lague, D., Brodu, N., and Leroux, J.: Accurate 3D comparison of complex topography with terrestrial laser scanner: Application to the Rangitikei canyon (N-Z), ISPRS J. Photogramm., 82, 10-26, doi:10.1016/j.isprsjprs.2013.04.009, 2013.

Lato, M. J., Hutchinson, D. J., Gauthier, D., Edwards, T., and Ondercin, M.: Comparison of ALS, TLS and terrestrial photogrammetry for mapping differential slope change in mountainous terrain, Can. Geotech. J., 52, 129-140, doi:10.1139/cgj-2014-0051, 2014.

Le Roux, O., Jongmans, D., Kasperski, J., Schwartz, S., Potherat, P., Lebrouc, V., Lagabrielle, R., and Meric, O.: Deep geophysical investigation of the large Séchilienne landslide (Western Alps, France) and calibration with geological data, Eng. Geol., 120, 18-31, doi:10.1016/j.enggeo.2011.03.004, 2011.

Levenberg, K.: A method for the solution of certain nonlinear problems in least squares, Q. Appl. Math., 2, 164-168, doi:10.1090/qam/10666, 1944 .

Lichti, D. D. and Licht, M. G.: Experiences with terrestrial laser scanner modelling and accuracy assessment, Int. Arch. Photogramm. Remote Sens. Spat Inf. Sci., doi:10.7202/706354ar, 2006.

Lichti, D. D., Gordon, S. J., and Tipdecho, T.: Error Models and Propagation in Directly Georeferenced Terrestrial Laser 
Scanner Networks, Journal of Surveying Engineerin, 131, 135-142, surveying engineering, doi:10.1061/(ASCE)07339453(2005)131:4(135), 2005.

Lim, M., Petley, D. N., Rosser, N. J., Allison, R. J., Long, A. J., and Pybus, D.: Combined Digital Photogrammetry and Time-of-Flight Laser Scanning for Monitoring Cliff Evolution, Photogrammetric Record, 20, 109-129, doi:10.1111/j.14779730.2005.00315.x, 2005.

Marquardt, D. W.: An algorithm for least-squares estimation of nonlinear parameters, J. Soc. Ind. Appl. Math. 11, 431-441, 1963.

Metternicht, G., Hurni, L., and Gogu, R.: Remote sensing of landslides: An analysis of the potential contribution to geo-spatial systems for hazard assessment in mountainous environments, Remote Sens. Environ., 98, 284-303, doi:10.1016/j.rse.2005.08.004, 2005.

Milan, D. J., Heritage, G. L., and Hetherington, D.: Application of a 3D laser scanner in the assessment of erosion and deposition volumes and channel change in a proglacial river, Earth Surf. Proc. Land., 32, 1657-1674, doi:10.1002/esp.1592, 2007.

Monserrat, O. and Crosetto, M.: Deformation measurement using terrestrial laser scanning data and least squares 3D surface matching, ISPRS J. Photogramm., 63, 142-154, doi:10.1016/j.isprsjprs.2007.07.008, 2008.

Muja, M. and Lowe, D. G.: Fast Approximate Nearest Neighbors with Automatic Algorithm Configuration, VISAPP, 2009.

Oppikofer, T., Jaboyedoff, M., and Keusen, H.-R.: Collapse at the eastern Eiger flank in the Swiss Alps, Nat. Geosci., 1, 531-535, doi:10.1038/ngeo258, 2008.

Oppikofer, T., Jaboyedoff, M., Blikra, L., Derron, M.-H., and Metzger, R.: Characterization and monitoring of the Åknes rockslide using terrestrial laser scanning, Nat. Hazards Earth Syst. Sci., 9, 1003-1019, doi:10.5194/nhess-9-1003-2009, 2009.

Orem, C. A. and Pelletier, J. D.: Quantifying the time scale of elevated geomorphic response following wildfires using multitemporal LiDAR data: An example from the Las Conchas fire, Jemez Mountains, New Mexico, Geomorphology, 232, 224-238, doi:10.1016/j.geomorph.2015.01.006, 2015.

Pothérat, P. and Alfonsi, P.: Les mouvements de versant de Séchilienne (Isère). Prise en compte de l'héritage structural pour leur simulation numérique, Revue française de géotechnique, 95-96, 2001.

Rosser, N. J., Petley, D. N., Lim, M., Dunning, S. A., and Allison, R. J.: Terrestrial laser scanning for monitoring the process of hard rock coastal cliff erosion, Q. J. Eng. Geol. Hydrogeol., 38, 363375, doi:10.1144/1470-9236/05-008, 2005.

Royán, M. J., Abellán, A., Jaboyedoff, M., Vilaplana, J. M., and Calvet, J.: Spatio-temporal analysis of rockfall pre-failure deformation using Terrestrial LiDAR, Landslides, 11, 697-709, doi:10.1007/s10346-013-0442-0, 2013.
Royán, M. J., Abellán, A., and Vilaplana, J. M.: Progressive failure leading to the 3 December 2013 rockfall at Puigcercós scarp (Catalonia, Spain), Landslides, 12, 585-595, doi:10.1007/s10346-015-0573-6, 2015.

Rusu, R. B. and Cousins, S.: 3D is here: Point Cloud Library (PCL), IEEE, 1-4, 2011.

Rusu, R. B., Blodow, N., and Beetz, M.: Fast point feature histograms (FPFH) for 3D registration, in: IEEE International Conference on Robotics and Automation (ICRA), 1848-1853, 2009.

Schürch, P., Densmore, A. L., Rosser, N. J., Lim, M., and McArdell, B. W.: Detection of surface change in complex topography using terrestrial laser scanning: application to the Illgraben debris-flow channel, Earth Surf. Proc. Land., 36, 1847-1859, doi:10.1002/esp.2206, 2011.

Teledyne Optech: ILRIS Terrestrial Laser Scanner, available at: http://www.teledyneoptech.com/wp-content/uploads/ ILRIS-Spec-Sheet-140730-WEB.pdf (last access: 15 January 2017), 2014a.

Teledyne Optech: Optech ILRIS Command Line User Manual, 2014b.

Teza, G., Galgaro, A., Zaltron, N., and Genevois, R.: Terrestrial laser scanner to detect landslide displacement fields: a new approach, Int. J. Remote Sensing, 28, 3425-3446, doi:10.1080/01431160601024234, 2007.

Travelletti, J., Oppikofer, T., and Delacourt, C.: Monitoring landslide displacements during a controlled rain experiment using a long-range terrestrial laser scanning (TLS), International Archives of Photogrammetry and Remote Sensing, 2008.

Vallet, A., Charlier, J. B., Fabbri, O., Bertrand, C., Carry, N., and Mudry, J.: Functioning and precipitation-displacement modelling of rainfall-induced deep-seated landslides subject to creep deformation, Landslides, 13, 653-670, doi:10.1007/s10346-0150592-3, 2015

Vulliez, C.: Apports des méthodes d'imagerie 3D pour la caractérisation et le monitoring du glissement rocheux de Séchilienne (Vallée de la Romanche, Isère, France), Lausanne, 12 February, 1-123, 2016.

Wang, C.-K. and Lu, Y.-Y.: Potential of ILRIS3D Intensity Data for Planar Surfaces Segmentation, Sensors, 9, 5770-5782, doi:10.3390/s90705770, 2009.

Wujanz, D., Krueger, D., and Neitzel, F.: Identification of Stable Areas in Unreferenced Laser Scans for Deformation Measurement, Photogramm. Rec., 31, 261-280, 2016.

Zhong, Y.: Intrinsic shape signatures: A shape descriptor for 3D object recognition, IEEE, 689-696, 2009. 